\title{
Identification, screening and stereotyping in labour market discrimination
}

\author{
Maarten C. M. Vendrik • Christiane Schwieren
}

Received: 17 April 2009 / Accepted: 1 December 2009 / Published online: 31 December 2009

C) The Author(s) 2009. This article is published with open access at Springerlink.com

\begin{abstract}
According to social-psychological research, feelings of uncertainty in decision-making evoke two opposite responses: (i) reduction of uncertainty by information search, leading to less stereotyping of people, and hence less discrimination; (ii) social identification with an ingroup, inducing more reliance on stereotypic perceptions and prejudices, and hence more discrimination against an outgroup. We integrate both responses in a microeconomic model of hiring and pay decisions by an employer. Increasing competition in the product market makes the employer feel more uncertain about his profits, but also raises the opportunity cost of screening expenditures. This elicits substitution of ingroup identification for screening expenditures, and hence enhances discrimination.
\end{abstract}

Keywords Discrimination $\cdot$ Stereotyping $\cdot$ Social identity $\cdot$ Uncertainty $\cdot$ Screening JEL Classification $\quad \mathrm{J} 7 \cdot \mathrm{M} 51$

\section{Introduction}

In the last 50 years a rich literature on discrimination has developed in social psychology (see Fiske 1998; Zanna and Olson 2004; Hewstone et al. 2002, for overviews).

\footnotetext{
M. C. M. Vendrik $(\bowtie)$

Maastricht University, P. O. Box 616, 6200 MD Maastricht, The Netherlands

e-mail: m.vendrik@maastrichtuniversity.nl

M. C. M. Vendrik

IZA, Bonn, Germany

C. Schwieren

University of Heidelberg, Heidelberg, Germany
} 
Some basic concepts in this literature, like prejudice and stereotyping, have been adopted in economics as well (see, e.g., Becker 1957, 1971; Altonji and Blank 1999). However, a sizable reservoir of potentially interesting findings for economics has so far remained untapped. One combination of such findings is the following. When a person feels uncertain about things that are important for him (or her), such as being able to make a living, he is, under certain circumstances, inclined to identify himself more strongly with a salient social group he belongs to (his ingroup, e.g., men, natives; see, e.g., Mullin and Hogg 1998). In its turn, this induces him to rely more on stereotypic perceptions and prejudices (see also Bodenhauser 1993), which can lead to more discrimination against members of an outgroup (e.g., women, foreigners).

A striking development in the Western world in which this psychological mechanism may have played an important role is that the upsurge of fear of terrorism after 11 September 2001, seems to have led to more stereotyping and discrimination against Muslims in the labour market ("we against them"; Sheridan and Gillett 2005; Sheridan 2006; see also Bar-Tal and Labin 2001). As quite a different example, agents may feel uncertain when they have to survive in an environment of fierce market competition. This seems especially relevant for people in former communist countries in their transition towards a market economy. ${ }^{1}$ The psychological prediction of increasing stereotyping may in particular play a role in relation to competition in the labour market: In regions within European countries where unemployment is higher, stereotypic perceptions about the roles of men and women tend to be stronger (see Sect. 5), leading to a larger gender gap in unemployment (Azmat et al. 2006). Rising competition in the product market may have a comparable effect. Boone et al. (2004) describe how in the newspaper-publisher industry powerful top-management teams become more homogeneous with respect to demographic characteristics when competition in the product market strengthens-by hiring demographically similar and firing dissimilar team members.

However, social-psychological research also suggests quite a different kind of response to increased feelings of uncertainty. Tiedens and Linton (2001) conducted an experimental study on individual decision-making focusing on the effects of uncertainty-related emotions on information processing and stereotyping. They find that stronger uncertainty-related emotions lead to a more thorough look at the individual information at hand and less reliance on stereotypes. This is the rational type of response that an economist could expect.

Thus, two opposite responses to increased feelings of uncertainty seem possible: a social-identity-based response and a rational "economic" response. This raises the question under which conditions one or the other response will occur or dominate. To answer this question, we build a microeconomic model that explains both the psychological identification mechanism and the "economic" response, and integrates them. It is formulated in terms of a simultaneous utility maximization with respect to ingroup identification on the one hand and screening expenditure on the other hand. The model addresses the way in which a risk-averse employer forms his expectation of the relative

\footnotetext{
1 The psychological prediction of increasing stereotyping and discrimination then is consistent with indications that, e.g., in Russia, the old stereotype that men should have a job and women should stay at home has revived, while at the same time labour market discrimination against women has increased (Hunt 1997).
} 
productivities of a number of equally qualified candidates for a position. He may base this expectation on individual information from job interviews, hiring tests, etc., but he may also use stereotypic information on the average productivities of groups candidates belong to (men/women, white/black, etc.). We then consider situations in which the employer starts to feel more uncertain about the level of his profits, especially situations of stronger competition. This is assumed to make the employer more (absolutely) risk averse with respect to the risk in his productivity estimates, which raises his utility loss due to this risk. This evokes two kinds of response to reduce the utility loss.

First, the employer may spend more money, time and cognitive energy on collecting individual information on candidates (cf. Tiedens and Linton 2001). This rise in screening expenditure (cf. Altonji and Blank 1999, p. 3190) raises the (perceived) reliability of the individual information, and hence induces the employer to give a higher weight to this individual information in his productivity estimates (cf. Phelps 1972; Aigner and Cain 1977). As a result, the (perceived) risk in the productivity estimates, and hence the ensuing utility loss, drops, and less use is made of stereotypic information.

However, screening is costly. As a second option, the employer may therefore respond to his increased feelings of uncertainty by identifying himself more strongly with his ingroup (cf. Mullin and Hogg 1998). This creates an "illusion of certainty" with respect to perceptions of group characteristics, which makes the employer perceive his stereotypic information on the average productivities of the ingroup and the outgroup as more reliable. As a result, the perceived risk in the productivity estimates, and hence the ensuing utility loss, again drops, but now more use is made of stereotypic information.

Thus, screening expenditure and ingroup identification are substitute means to reduce the perceived risk in the productivity estimates of applicants, and hence the ensuing utility loss. The degrees to which screening expenditure or ingroup identification are used by the employer to reduce the felt risk determines whether the use of stereotypic information in the productivity estimates will fall or rise. To investigate under which conditions one or the other will happen, we derive expressions for simultaneous equilibrium levels of screening expenditure and ingroup identification dependent on certain other variables. Since social identification is more salient in group situations, we assume that the employer is the residual claimant in a production team (as in the classic entrepreneurial firm of Alchian and Demsetz 1972) most members of which belong to the ingroup of the employer. In such a context the employer will easily identify with his ingroup, and hence use this identification to reduce the felt risk. This marginal benefit of ingroup identification is assumed to be balanced by a marginal cost from less personal identity (“depersonalization"; e.g., Turner 1984). The implied endogenization of ingroup identification represents a novelty of the model. ${ }^{2}$

A surprising implication of our (linearized) model is that when the employer becomes more uncertain about his profits, and hence more risk averse, screening

\footnotetext{
2 Akerlof and Kranton (2000) give an interesting general analysis of the impact of social identity on economic outcomes. They also analyze the choice of a particular ingroup to identify with (pp. 725-726), but they do not model the determination of the level of ingroup identification, as we do.
} 
expenditure unambiguously rises, but ingroup identification does not change (ceteris paribus). In particular, this effect occurs when increasing competition on the supply side of the product market lowers profits, and hence raises the risk of bankruptcy. However, lower profits also imply a tighter budget for expenditures, and hence raise the opportunity cost of screening expenditures. This elicits substitution of ingroup identification for these expenditures as a means to reduce the felt risk. For a common power specification of the employer's utility function of profit, the resulting rise in identification is shown to dominate the counteracting 'economic' effects in leading to a higher use of the stereotypic perception for 'most' profit levels. This implies an increase in individual statistical discrimination. Moreover, in the case of group discrimination, the implied discrimination coefficient of the employer rises as competition strengthens at sufficiently low profit levels. Competition in the product market then raises group discrimination even when no differences in real productivity distribution and in reliability of individual information between the ingroup and the outgroup exist, so even when discrimination is not rational from a profit-maximizing point of view.

Other economic models (e.g., of employee and customer discrimination, search costs, statistical discrimination, imperfect competition, self-fulfilling prophecies, gender differences in efficiency-wage effects, wage bargaining; see, e.g., Altonji and Blank 1999; Coate and Loury 1993; Haagsma 1993; Rosen 2003) are able to explain that discrimination can be persistent under strengthening competition in the product market, but none of them predicts that inefficient discrimination which is not based on differences in variance of the productivity distribution or reliability of individual information between groups may even increase under competitive pressure ${ }^{3}$ (see Weichselbaumer and Winter-Ebmer 2007, for a recent overview of the empirical and theoretical literature). More importantly, (almost) all economic models seem to assume that the extents to which employers rely on stereotypic perceptions and prejudice are fixed and do not change endogenously. Both social-psychological research and the empirical evidence mentioned above suggest that the degree of reliance on stereotypes and prejudices is influenced by the socio-economic context. In particular, it may become stronger when competition intensifies, leading to an increase in discrimination.

This paper endogenizes reliance on stereotypes and prejudices in a microeconomic model integrating social-psychological findings. The main application of the model is the discrimination-raising effect of competition in the product market, but we also consider the impact of fear of terrorism, increasing labour supply competition (unemployment $)^{4}$, and affirmative action. Finally, at the end of the paper, we review some related empirical and experimental evidence.

The organization of the paper is as follows. Section 2 develops the basic model, which simultaneously determines the screening expenditure on a job applicant and

\footnotetext{
3 When there is a difference in variance of the productivity distribution or reliability of individual information between the ingroup and the outgroup in favour of the ingroup, rising risk aversion as a result of increasing competitive pressure will raise discrimination against the outgroup (see Aigner and Cain 1977; Hendricks et al. 2003; see also Cornell and Welch 1996). Shleifer (2004) finds that under strong competition unethical cost-reducing behaviour becomes more tempting, and thus can lead to more (efficient) discrimination. However, these are not the kinds of mechanism that we model in this paper.

4 The focus of this paper is on the effects of product supply competition since for this kind of competition it is much less obvious that it may raise discrimination than for labour supply competition.
} 
identification with the ingroup. Section 3 analyses the implied effects of competition in the product market, fear of the outgroup, unemployment, and affirmative action on individual statistical discrimination. Robustness and extensions of the basic model are discussed in Sect. 4, with special attention to the possible effects of competition on group discrimination. Section 5 reports some related empirical evidence, and Sect. 6 concludes.

\section{The basic model}

\subsection{Basic assumptions and relations}

Consider a representative firm that produces one homogeneous good and sells it in a competitive market. The number of competitors in this market is large so that the firm is a price taker, but profits are still positive due to entry barriers. The internal structure of the firm is that of a production team one member of which takes decisions on, among other things, hiring and pay of new team members (Alchian and Demsetz 1972). This employer receives the firm's residual income, i.e., the profit, while the other team members earn fixed wages. Most team members belong to a certain ingroup of the employer, consisting of equally qualified individuals (e.g., men, natives; the same for all employers in the market), but new team members can be hired from the ingroup as well as from the equally qualified outgroup (e.g., women, foreigners). Within these groups marginal team productivities $q_{i}$, i.e., marginal contributions of new team members $i$ to the prevailing team production, vary, but between the groups no real differences in the distribution of $q_{i}$ exist except for a possible difference in average $\bar{q}$.

The employer has imperfect information about the productivities $q_{i}$ in the ingroup and the outgroup (but perfect information about other variables like the product price in the market). Therefore, he has to form subjective expectations $\hat{q}_{i}$ of the $q_{i}$ of individual candidate team members. The employer bases these expectations on two different sources. First, to save on search for information on individual productivities, he bases his expectation $\hat{q}_{i}$ on stereotypic group perceptions $\bar{q}^{S}$ of the average marginal team productivities $\bar{q}$ of the two groups. The perception $\bar{q} S O$ of the outgroup differs from the perception $\bar{q}$ SI of the ingroup. In line with the basic idea of outgroup discrimination, we assume $\bar{q}^{S O}<\bar{q}^{S I}$, but the model also allows for the possibility that $\bar{q}^{S O}>\bar{q}^{S I}$ (see Sect. 4.1). Secondly, to reduce the risk in his estimates of individual productivities, the employer collects information about individual candidates, e.g., by means of hiring tests. Assume that, in the perception of the employer, this individual information yields unbiased, but imperfectly reliable estimates $q_{i}^{T}$ of individual $q_{i}$ 's. More specifically, $q_{i}^{T}=q_{i}+u_{i}$, where $u_{i}$ is a normally distributed error term, independent of $q_{i}$, with zero mean and constant variance.

Furthermore, for ingroup as well as outgroup members productivity $q_{i}$ has a prior subjective probability distribution, which is normal, with mean equal to the stereotypic perception $\bar{q}^{S}$ (different for ingroup and outgroup members) and constant variance (equal for ingroup and outgroup members). The posterior (subjective) expected value 
of $q_{i}$, given the individual test estimate $q_{i}^{T}$, then is:

$$
\hat{q}_{i} \equiv E\left(q_{i} \mid q_{i}^{T}\right)=S \bar{q}^{S}+(1-S) q_{i}^{T}
$$

where

$$
S=\frac{R^{S}}{R^{S}+R^{T}} .
$$

Here the coefficient $S \in[0,1]$ represents the extent to which the employer uses his stereotypic perception $\bar{q}^{S}$ in the formation of his productivity estimate $\hat{q}_{i}$. The variable $R^{S}$ denotes the perceived reliability of the stereotypic group information $\bar{q}^{S}$ as an indicator of the individual productivity $q_{i}$ and is defined as the inverse of the variance of the prior probability distribution of $q_{i}$ (see above). ${ }^{5}$ The variable $R^{T}$ stands for the perceived reliability of the individual information $q_{i}^{T}$ and is defined as the inverse of the variance of its error $u_{i}$ (see above). ${ }^{6}$ Since the variances are assumed to be the same for the ingroup and the outgroup, $S$ is the same for ingroup and outgroup members. Thus, the intuitively appealing Eq. (2) indicates that the extent to which the team members use their stereotypic perceptions in the formation of their productivity expectations equals the perceived reliability of this stereotypic information relative to the sum of the reliabilities of the two types of information. The next sections will show how these reliabilities, and hence the extent of using stereotypes, can change as a result of changes in financial-economic and psychological choice variables.

The feature that the individual productivity estimates $\hat{q}_{i}$ are partially based on perceived group averages implies individual statistical discrimination in hiring and pay. Assuming that the individual test estimates $q_{i}^{T}$ are unbiased not only in the perception of the employer, but also in reality (see Sect. 4.1 about a relaxation of this assumption), taking objective expectations conditional on $q_{i}$ in (1) yields

$$
E^{o}\left(\hat{q}_{i} \mid q_{i}\right)=S \bar{q}^{S}+(1-S) q_{i}=S\left(\bar{q}^{S}-q_{i}\right)+q_{i}
$$

Deviation $E^{o}\left(\hat{q}_{i} \mid q_{i}\right)-q_{i}$ can be interpreted as a measure of positive/negative individual (i.e., within-group) discrimination. Equation (3) then implies that this measure equals $S\left(\bar{q}^{S}-q_{i}\right)$. Thus, in absolute value it is linearly increasing in the extent of stereotyping $S$. Equation (3) has also implications for group discrimination, but these will be elaborated in Sect. 4.2.

The model that we develop in this paper can be applied to three situations. In the simplest Situation 1 new employees are assumed to be hired for a certain job level with one fixed wage $w$, which is given to and identical across firms. The employers

\footnotetext{
$5 R^{S}$ has two components: (i) the reliability of $\bar{q}$ as an indicator of the average productivity of ingroup/outgroup members $\bar{q}$ and (ii) the reliability of $\bar{q}$ as an indicator of individual productivity $q_{i}$. See Appendix A for a further explanation of this decomposition.

6 See Phelps (1972) and Aigner and Cain (1977) for the formula for $S$ in terms of variances. Note that $S$ corresponds to the coefficient $1-\gamma$ of average productivity $\alpha$ in Eq. (2) of Aigner and Cain (1977).
} 
then hire the candidates with the highest marginal productivity $\hat{q}_{i} \cdot{ }^{7}$ In this situation there is discrimination in hiring, but not in pay. The model derivations in the following sections are given for this situation. In another Situation 2 there is discrimination not only in hiring, but also in pay, while in Situation 3 there is discrimination in pay, but not in hiring. The derivations for these situations are slightly different, but have analogous implications. They will be discussed in Sect. 4.1.

\subsection{Screening expenditure}

The perceived reliability of individual information $R^{T}$ is determined by the amounts of money, time and cognitive energy that are spent on collecting information on the productivity $q_{i}$ of an individual candidate (e.g., by means of a hiring test). We can express all these expenditures in terms of one monetary measure by noting that time and cognitive energy have monetary opportunity costs given by the revenues from spending time and cognitive energy on the most profitable alternative activities. The total expenditures for candidate $i$ are referred to as screening expenditure $X$ (assumed to be the same for each candidate; cf. Altonji and Blank 1999, p. 3190). This $X$ represents an endogenous choice variable of the employer. By raising $X$ the employer can make the individual information more reliable, i.e., raise reliability $R^{T}$. In its turn, this lowers the use of stereotypic information $S$ by virtue of (2). As described in Sect. 1, raising screening expenditure is one of two options the employer has in our model to reduce the perceived risk with respect to the productivity of a candidate. In the following we show how screening expenditure $X$ is determined by the employer in relation to the other option, rising identification with a salient ingroup.

The employer chooses screening expenditure $X$ at the level at which the expected marginal benefit of $X$ for the employer is equal to its expected marginal cost. These marginal benefit and cost are implied by:

Assumption 1 The employer maximizes a one-period utility function which has the general form

$$
U(X, I)=E^{a}\left[E^{p}\left(U^{\Pi}(\Pi)\right)\right](X, I)+U^{I}(I) .
$$

Here $I$ is identification of the employer with his ingroup. The first term on the righthand side denotes the ex ante (i.e., before screening) expected value of the ex post (i.e., after screening) expected utility of profit $\Pi$ in the extended team, i.e., including a new team member. Profit $\Pi$ is stochastic due to the risk in the marginal productivity $q_{i}$ of a new team member, ${ }^{8}$ and in addition its ex post expected value is stochastic ex

\footnotetext{
7 Thus, because of its unreliability, the individual test information on job applicants is only used for selection in hiring, but not as a basis for individual variation in wages (see, however, Situation 3 in Sect. 4.1). Furthermore, there is no difference in risk premium for ingroup versus outgroup members since we assume equal perceived variances of $\hat{q}_{i}$ for ingroup and outgroup members.

8 The productivity of the existing team is assumed to be perfectly predictable because of the knowledge of production levels of the existing team in the past (neglecting fluctuations). See Sect. 4.1 for a relaxation of this assumption.
} 
ante since the individual test estimate $q_{i}^{T}$ has yet to be made. An important assumption (in line with Aigner and Cain 1977; Hendricks et al. 2003) is:

Assumption 2 Utility (component) function $U^{\Pi}$ has positive and diminishing marginal utility, implying risk aversion.

This assumption can be justified by presuming that capital markets work imperfectly and/or that the employer does not like the firm to go bankrupt since he is committed to the firm or fears loss of reputation in the market of employers from bankruptcy. ${ }^{9}$ The second component $U^{I}(I)$ of utility function (4) indicates the utility of general benefits and costs of $I$ (see next section). ${ }^{10}$

Profit $\Pi$ in the extended team depends negatively on screening expenditure $X$ as this is part of the total costs of the team. Besides its cost, $X$ also has the benefit of raising the reliability of individual information $R^{T}$ (see above), and hence, logically, of reducing the perceived risk in the productivity $q_{i}$ of a new team member. ${ }^{11}$ This risk is represented by the posterior conditional variance $\sigma^{2}$ (assumed to be independent of $i$ ), i.e., the perceived variance of $q_{i}$ around its posterior estimate $\hat{q}_{i}$ as given by (1). The effect of this risk in the individual productivity of a new team member on the utility of the employer can be rendered visible by making a second-order Taylor expansion of $U^{\Pi}(\Pi)$ around the ex post (i.e., posterior) expected value $\hat{\Pi}$ of profit $\Pi$ (as usual in risk analysis; see, e.g., Nicholson 1998, p. 223; see Appendix A for this and following approximations). ${ }^{12}$ Making some further approximations and a first-order Taylor expansion with respect to the number of screened candidates $m$ times $X$, based on the plausible assumption that total screening expenditures $m X$ are low relative to profit $\hat{\Pi}$, we then obtain

Assumption 3 The first component of utility function (4) is given by:

$$
E^{a}\left[E^{p}\left(U^{\Pi}(\Pi)\right)\right]=U^{\Pi}\left(\hat{\Pi}_{0}^{S}\right)-U^{\Pi \prime}\left(\hat{\Pi}_{0}^{S}\right) m X+\frac{1}{2} U^{\Pi \prime \prime}\left(\hat{\Pi}_{0}^{S}\right) p^{2} \sigma^{2}
$$

Here $\hat{\Pi}_{0}^{S} \equiv E^{a}(\hat{\Pi})$ for $m X=0$, which is obtained by replacing $\hat{q}_{i}$ by its prior expectation $\bar{q}$ and omitting $m X$ in $\hat{\Pi}$. Furthermore, $m$ is assumed to be exogenously determined by a limited supply of equally best-qualified candidates. Since utility component $U^{I}(I)$ in (4) does not depend on $X$, (5) gives an expression for maximand $U(X)$. The second term of this expression represents the expected opportunity cost of

\footnotetext{
9 Alternatively, risk aversion may be due to a negative dependence of profits on unpredictable variation in the $q_{i}$ of team members (cf. Aigner and Cain 1977, p. 181).

10 This utility should not be confused with the disutility due to prejudice in Becker's (1957) theory of employer discrimination. See Sect. 4.2 for that.

11 Of course, also some expenditure has to be made to select the set of (more or less) equally best-qualified candidates. This expenditure, however, is not included in $X$.

12 This is not equivalent to assuming a quadratic specification of $U^{\Pi}(\Pi)$ since this Taylor expansion is only used as a local approximation of $U^{\Pi}(\Pi)$ for $\Pi$ near $\hat{\Pi}$, and hence is still consistent with a general utility function $U^{\Pi}(\hat{\Pi})$. Mutatis mutandis, this holds for the following approximations in this Sect. 2 as well. See Sect. 4.2 for the special and counterintuitive case of an additive quadratic specification of $U^{\Pi}(\hat{\Pi})$.
} 
the total screening expenditures for the employer in terms of utility. The last term indicates the ex ante expected utility loss due to the perceived risk of making mistakes in the individual productivity estimates. This risk is what we mean by the perceived risk in the individual productivity of a new team member. As indicator of this perceived risk serves variance $\sigma^{2}$. This variance can be shown to be related to the perceived reliabilities of the individual and stereotypic information as

$$
\sigma^{2}=\frac{1}{R^{S}+R^{T}}
$$

(see Appendix A). Hence, a rise in the reliability of the individual or stereotypic information reduces the perceived risk in the individual productivity of a new team member.

As argued above, the employer can raise the reliability of individual productivity information on a candidate new member by raising his screening expenditure. To obtain an explicit solution for the utility-maximizing amount of screening expenditure $X^{*}$, and to thus make the model more transparent, we make the following linear approximation:

Assumption 4 The reliability of individual productivity information $R^{T}$ as a function of screening expenditure $X$ is given by $R^{T}(X)=\alpha X$, where $\alpha$ is a positive parameter.

This assumption implies that the corresponding variance of error $u_{i}$ in individual productivity estimate $q_{i}^{T}$ as a function of $X$ equals $\alpha^{-1} X^{-1}$ with elasticity -1 , which represents an intermediate case. ${ }^{13}$ Substituting the linear formula for $R^{T}$ into (6) for variance $\sigma^{2}$, substituting the resulting expression into the formula for the expected utility loss in (5), and differentiating utility function (5) to $X$ yields the first-order condition for an interior utility-maximizing level of screening expenditure $X^{*}$

$$
\frac{\left|U^{\Pi \prime \prime}\left(\hat{\Pi}_{0}^{S}\right)\right| p^{2} \alpha}{2\left(R^{S}+\alpha X^{*}\right)^{2}}=U^{\Pi \prime}\left(\hat{\Pi}_{0}^{S}\right) m .
$$

The left-hand side of this condition represents the expected marginal benefit for the employer of higher screening expenditure per candidate $X$. It is given by the ex ante expected reduction of the utility loss due to the risk in the productivity estimate of a new team member, and it is falling as a function of $X$. The right-hand side of condition (7) shows the expected marginal cost of a higher $X$ as the expected marginal disutility of screening expenditures $m X$. It is constant with respect to $X$. Solving condition (7) for $X^{*}$ then leads to a very simple expression for the optimal $X^{*}$, as formulated in the following proposition:

\footnotetext{
13 This is a special case of variance $V(u)(X)=X^{-\varepsilon}$ for $\varepsilon=1$ (dropping constant $\alpha^{-1}$ ). For positive $\varepsilon$ this implies $V(u)^{\prime \prime}(X)=\varepsilon(\varepsilon+1) X^{-\varepsilon-2}>0$, i.e the plausible property of diminishing marginal reduction in variance $V(u)$ as $X$ rises. It also implies $R^{T}(X)=1 / V(u)(X)=X^{\varepsilon}$ with $R^{T \prime \prime}(X)=\varepsilon(\varepsilon-1) X^{\varepsilon-2}$, which is negative if $\varepsilon<1$, but positive if $\varepsilon>1$. See Sect. 4.2 and Vendrik and Schwieren (2005) for more general results when the linear approximation of $R^{T}(X)$ for $\varepsilon=1$ is not made.
} 
Proposition 1 There is a unique utility-maximizing level of screening expenditure $X^{*}$, conditional on I, given by

$$
X^{*}=p \sqrt{\frac{r\left(\hat{\Pi}_{0}^{S}\right)}{2 m \alpha}}-\frac{R^{S}}{\alpha} \geq 0
$$

or $X^{*}=0$ if the expression in (8) is negative.

Here $r\left(\hat{\Pi}_{0}^{S}\right)$ is defined as Pratt's measure of risk aversion $\left|U^{\Pi \prime \prime}\left(\hat{\Pi}_{0}^{S}\right)\right| / U^{\Pi \prime}\left(\hat{\Pi}_{0}^{S}\right)$ of the employer. Thus, the utility-maximizing screening expenditure by the employer depends positively on his risk aversion and the product price $p$, and negatively on the number of screened candidates $m$ and the perceived reliability of the stereotypic information $R^{S}$. The next subsection will show how $R^{S}$ can vary as a result of a change in ingroup identification $I^{*}$. By virtue of (8) this will then also affect the optimal screening expenditure.

\subsection{Identification}

A social-psychological prediction we want to incorporate into the model is that when someone experiences self-relevant uncertainty, he is inclined to identify himself with a salient ingroup (e.g., men; Mullin and Hogg 1998). Experiencing self-relevant uncertainty means feeling uncertain about things that are important in one's life and for one's self-definition, such as having a job or being able to make a living (note that we are speaking about a subjective experience of uncertainty). Self-relevant uncertainty is experienced as aversive, and therefore people tend to react by identifying themselves with their ingroup. By depersonalizing they perceive themselves more as group members and less as individuals. This allows them to base their judgments and decisions on "normative" judgments and decisions of their respective ingroup. Group membership provides them with perceptions of right and wrong and standards of behaviour (Turner 1984). This creates a kind of "certainty illusion". It diminishes self-relevant uncertainty and, at the same time, induces people to rely more on stereotypes and prejudice in their decisions.

How do these social-psychological processes fit into our microeconomic model? The basic problem is a suitable interpretation of the concept of self-relevant uncertainty $(S R U C)$ in the context of the model. Let us start with some observations. First, $S R U C$ is a perception accompanied by a negative emotion. Second, SRUC can increase in two ways: (i) the subjectively perceived uncertainty $(U C)$ about important things may increase, (ii) the self-relevancy $(S R)$, i.e., subjective importance, of the things one is uncertain about increases. This observation suggests to operationalize the concept of $S R U C$ as a product of self-relevancy $S R$ and uncertainty $U C$. Moreover, we can interpret self-relevancy $S R$ as the subjective importance of uncertainty $U C$ for the (overall) subjective well-being of a person. Multiplying $S R$ with $U C$ then yields the perceived loss or gain in well-being due to the uncertainty, where the loss holds for 
risk-averse persons and the gain for risk-loving persons. ${ }^{14}$ In the context of our model, we can then make the following assumption.

Assumption 5 Uncertainty UC of the employer is given by the perceived risk $\sigma^{2}$ in the productivity of a new team member, and the corresponding self-relevant uncertainty SRUC of the employer is the ex ante expected utility loss due to this risk that is given by the last term of utility function (5).

Uncertainty $U C$ can be considered as self-relevant since it implies, for sufficiently low levels of profits, a substantial risk of negative profits, and hence bankruptcy. Accordingly, for higher levels of profits self-relevancy $S R$ would be lower. The expression for the expected utility loss in (5) implies that the self-relevancy of risk $\sigma^{2}$ is equal to $\frac{1}{2}\left|U^{\Pi \prime \prime}\left(\hat{\Pi}_{0}^{S}\right)\right| p^{2}$, and so proportional to absolute risk aversion $\left|U^{\Pi \prime \prime}\left(\hat{\Pi}_{0}^{S}\right)\right|^{15}$ and product price squared $p^{2}$ (see Sect. 3.1 for more on this).

The previous section has shown that one way in which the employer can reduce the perceived risk $\sigma^{2}$ in the productivity of a new team member, and hence his selfrelevant uncertainty, is raising his screening expenditure. However, this is costly, and in the given social context an alternative, possibly less costly means to reduce his self-relevant uncertainty is raising his identification with his ingroup $I$. The resulting stronger "certainty illusion" of the employer can be interpreted as leading to a higher perceived reliability $R^{S}$ of the stereotypic information on the productivity of a new team member, and hence by virtue of (6) to a lower perceived risk $\sigma^{2}$, and so a lower self-relevant uncertainty. The stronger identification of the employer with his ingroup can raise $R^{S}$ in two ways: (i) by a stronger focus on stereotypes it leads to a higher perceived reliability of the stereotypic perceptions $\bar{q}^{S}$ as indicators of average productivity $\bar{q}$ for ingroup as well as outgroup members (see the decomposition of $R^{S}$ in footnote 5), and (ii) it raises the perceived reliability of $\bar{q}$ as an indicator of individual productivity $q_{i}$ for ingroup as well as outgroup members. ${ }^{16}$

Just as in the case of screening expenditure, we ask how the level of ingroup identification by the employer $I$ is determined. To answer this question, we assume, in line with social-identity theory, that people have a personal identity and one or more ingroup identities. In some situations the personal identity, in others a specific ingroup identity is more salient. Accordingly, we define $I$ more precisely as the degree to which

\footnotetext{
14 Thus, uncertainty $U C$ is interpreted as perceived risk. This deviates from the standard use in economic literature in which "uncertainty" is uncertainty in the Knightean sense. We assume the mechanism described to hold for risk as well as uncertainty in the Knightean sense, but formulate the model in terms of risk. However, when dealing with the psychological concept of self-relevant uncertainty, we use the terms uncertainty and risk interchangeably. Strictly speaking, the psychological concept of self-relevant uncertainty only applies to risk-averse persons since it involves a negative emotion. By allowing the emotion to be positive it could be extended to risk-loving people.

15 While Pratt's measure of risk aversion $r\left(\hat{\Pi}_{0}^{S}\right)$ is a determinant of risk premia in terms of money, $\left|U^{\Pi \prime \prime}\left(\hat{\Pi}_{0}^{S}\right)\right|$ is a determinant of the utility loss due to risk, and can therefore be considered as a measure of absolute risk aversion in terms of utility.

16 Both the ingroup and outgroup are perceived as more homogeneous with respect to marginal team productivity See, for example, De Cremer (2001), who gives an overview of the social-psychological literature on ingroup and outgroup-homogeneity effects.
} 
a specific ingroup identity is salient as compared to the personal identity. ${ }^{17}$ Hence, $I$ is continuously variable between 0 (zero weight of ingroup identity) and 1 (100\% weight of ingroup identity). Moreover, we assume that it is not generally optimal in terms of individual well-being to identify fully with an ingroup at the expense of the personal identity $(I=1)$. It seems more plausible to suppose that for a certain $I^{*}$ between 0 and 1 there is an optimal balance between ingroup identity with weight $I^{*}$ and personal identity with weight $1-I^{*}$ (cf. Brewer 1991). One important determinant of this optimal balance is the need for reduction of self-relevant uncertainty (see Mullin and Hogg 1998). In particular, the self-relevant uncertainty due to the perceived risk in the productivity of a new team member is reduced as ingroup identification rises. On the other hand, there are marginal costs from "depersonalization", i.e., less personal identity, for which a psychological need exists as well. The marginal benefits and costs of ingroup identification act as psychological forces, which are assumed to stabilize (temporarily) on an equilibrium of these forces. This homeostatic equilibrium optimizes the personal well-being in a subconscious way. In addition, this subconscious optimizing of well-being with respect to ingroup identification is assumed to be interrelated with the more conscious optimizing of utility or well-being with respect to screening expenditure (in line with the strong interconnectedness of conscious and subconscious processes that is shown in psychology; e.g., Bargh and Williams 2006). This is modeled as the interrelated maximization of the employer's utility function (4) with respect to $I$ and $X$.

Again using Taylor expansion (5), omitting the constant $U^{\Pi}\left(\hat{\Pi}_{0}^{S}\right)$, substituting (6) for $\sigma^{2}$, using Assumption 4, and rearranging terms, maximand $U(X, I)$ is given by

$$
U(X, I) \cong U^{I}(I)+\frac{U^{\Pi \prime \prime}\left(\hat{\Pi}_{0}^{S}\right) p^{2}}{2\left(R^{S}(I)+\alpha X\right)}-U^{\Pi \prime}\left(\hat{\Pi}_{0}^{S}\right) m X
$$

Here $U^{I}(I)$ represents the utility of all benefits and costs of ingroup identification apart from the benefit of reduction of self-relevant uncertainty due to the perceived productivity risk. It is strictly concave with positive marginal utility for $I<I_{0}$, a satiation point at $I=I_{0}$, and negative marginal utility for $I>I_{0}$. Thus, if there were no productivity risk, the employer would reach a psychological identification equilibrium at $I_{0}$, at which his utility $U^{I}(I)$ is maximal with respect to ingroup identification. However, the employer also likes to reduce his self-relevant uncertainty due to the perceived productivity risk, which is indicated by the second, utility loss term on the right-hand side of (9). By raising his ingroup identification beyond its "base level" $I_{0}$, the employer can increase the perceived reliability of stereotypic productivity information $R^{S}(I)$, and hence lower his utility loss. The utility loss can also be reduced by increasing screening expenditure $X$, and hence the reliability of individual productivity information $\alpha X$. But this has costs that are indicated by the last term in (9).

\footnotetext{
17 For the sake of simplicity, we assume that there is only one ingroup with which the employer identifies. This is a reasonable assumption for our specific situation.
} 
To obtain explicit solutions for the employer's utility-maximizing level of ingroup identification $I^{*}$, conditional on $X$, and for $I^{*}$, simultaneous with $X^{*}$, we make two approximations:

Assumption 6 Utility (component) function $U^{I}(I)$ is given by

$$
U^{I}(I)=U^{I}\left(I_{0}\right)+\frac{1}{2} U^{I \prime \prime}\left(I_{0}\right)\left(I-I_{0}\right)^{2}, \quad \text { where } U^{I \prime \prime}\left(I_{0}\right)<0
$$

Assumption 7 The perceived reliability of stereotypic productivity information $R^{S}$ as a function of ingroup identification I is given by $R^{S}(I)=\beta I$, where $\beta$ is a positive parameter.

Assumption 6 approximates $U^{I}(I)$ by its second-order Taylor expansion around the optimal "base level" $I_{0}$ (note that $U^{I^{\prime}}\left(I_{0}\right)=0$ ). Assumption 7 implies that the corresponding prior variance of productivity $q_{i}$ around stereotypic perception $\bar{q}^{S}$ as a function of $I$ equals $\beta^{-1} I^{-1}$ with elasticity -1 (which represents an intermediate case; see the previous section). Using these assumptions, the first-order condition for maximization of utility function (9) with respect to $I$ at given $X$ can be written as

$$
\left.\frac{\left|U^{\Pi \prime \prime}\left(\hat{\Pi}_{0}^{S}\right)\right| p^{2} \beta}{2\left(\beta I^{*}+\alpha X\right)^{2}}=\mid U^{I \prime \prime} I_{0}\right) \mid\left(I^{*}-I_{0}\right)
$$

Here the left-hand side represents the marginal benefit for the employer of higher ingroup identification. It is falling as a function of $I^{*}$. The right-hand side stands for the marginal cost of raising his ingroup identification above its "base level" $I_{0}$. This marginal cost is rising as a function of $I^{*}$. Solving condition (11) for $I^{*}$, conditional on $X$, and for $I^{*}$, simultaneous with $X^{*}$, then leads to (see Appendix A):

Proposition 2 a. There is a unique utility-maximizing level of ingroup identification $I^{*}$, conditional on screening expenditure $X$, that, if $\beta\left(I^{*}-I_{0}\right) \ll R_{0} \equiv \beta I_{0}+\alpha X$, is approximately given by

$$
I^{*}=I_{0}+\frac{R_{0}}{4 \beta}\left(\sqrt{1+\frac{4 \beta^{2}\left|U^{\Pi \prime \prime}\left(\hat{\Pi}_{0}^{S}\right)\right| p^{2}}{\left|U^{I \prime \prime}\left(I_{0}\right)\right| R_{0}^{3}}}-1\right)
$$

b. There is a unique utility-maximizing level of ingroup identification $I^{*}$, simultaneous with $X^{*}$, that is given by

$$
I^{*}=I_{0}+\frac{\beta m U^{\Pi \prime}\left(\hat{\Pi}_{0}^{S}\right)}{\alpha\left|U^{I \prime \prime}\left(I_{0}\right)\right|}
$$

for $I^{*} \leq p \sqrt{\alpha r\left(\hat{\Pi}_{0}^{S}\right) / 2 m} / \beta$, and by (12) with $X=0$ for higher $I^{*}$. 
Expression (12) indicates that, for given $X, I^{*}$ depends positively on risk aversion measure $\left|U^{\Pi \prime \prime}\left(\hat{\Pi}_{0}^{S}\right)\right|$ and product price $p$, and negatively on the rate of increase $\left|U^{I \prime \prime}\left(I_{0}\right)\right|$ of the marginal cost of ingroup identification. Equation (13) says that the simultaneous $I^{*}$ depends positively on the marginal productivity $\beta$ of ingroup identification in raising the perceived reliability of stereotypic information and on the marginal opportunity cost $m U^{\Pi^{\prime}}\left(\hat{\Pi}_{0}^{S}\right)$ of screening expenditure, and negatively on the marginal productivity $\alpha$ of screening expenditure in raising the reliability of individual information and on the rate of increase $\left|U^{I \prime \prime}\left(I_{0}\right)\right|$ of the marginal cost of identification. The condition under (13) corresponds to the case where the inequality in (8) is fulfilled. If it is not fulfilled, screening expenditure $X^{*}$ equals zero with lower marginal benefit than marginal cost, which implies that (7), and hence (13), no longer holds. Substituting (13) into $R^{S^{*}}=\beta I^{*}$, and the resulting expression into (8), we obtain the formula for simultaneous screening expenditure $X^{*} \geq 0$. Both the expressions for $I^{*}$ and $X^{*}$ clearly show the positive substitution effects of a rise in (the rate of increase of) the marginal opportunity cost of one of them on the optimal level of the other one.

In the context of this paper, we are especially interested in the effects of changes in risk aversion of the employer (see Sect. 3.1). Suppose absolute risk aversion $\left|U^{\Pi \prime}\left(\hat{\Pi}_{0}^{S}\right)\right|$ rises, ceteris paribus. Then self-relevant uncertainty (=minus the second utility-loss term in (9)) and the expected marginal benefit of ingroup identification in (11) rise as well. Equation (12) shows that this leads to an increase in ingroup identification for given level of screening expenditure, which is consistent with findings in social psychology (e.g., Mullin and Hogg 1998). Surprisingly, however, (13) indicates that ingroup identification, simultaneous with positive screening expenditure, does not depend on risk aversion $\left|U^{\Pi \prime \prime}\left(\hat{\Pi}_{0}^{S}\right)\right|$, implying

Corollary 1 If absolute risk aversion $\left|U^{\Pi \prime \prime}\left(\hat{\Pi}_{0}^{S}\right)\right|$, and hence self-relevant uncertainty and expected marginal benefits of ingroup identification, increases c.p.,

a. ingroup identification $I^{*}$, conditional on screening expenditure $X$, rises, but

b. ingroup identification $I^{*}$, simultaneous with positive screening expenditure $X^{*}$, does not change.

The result under $\mathrm{b}$ is due to the accommodating rise in screening expenditure $X^{*}$ when risk aversion $\left|U^{\Pi \prime \prime}\left(\hat{\Pi}_{0}^{S}\right)\right|$, and hence the expected marginal benefit of screening expenditure, increases (see (7) and (8)). The rise in $X^{*}$ raises the perceived reliability of individual productivity information $R^{T^{*}}$, which lowers the perceived risk $\sigma^{2}$ in the productivity of a new team member (6). This lowers the expected marginal benefit of ingroup identification in (11), and hence leads to a lower ingroup identification $I^{*}$. Since the marginal-cost-of-screening-expenditure curve is horizontal by approximation (see Assumption 3 and (7)), the rise in screening expenditure is considerable, and apparently pushes ingroup identification back to its original level. Thus, the rise in screening expenditure fully substitutes for the initial rise in ingroup identification in reducing self-relevant uncertainty. This possibility of full substitution of $X$ for $I$, but not the reverse, is due to our approximation of a constant marginal cost of screening expenditure. This, however, is a plausible approximation (see the auxiliary assumption above Assumption 3) and suffices for the applications of the model in Sect. 3. 


\subsection{Stereotyping}

What are the consequences of the equilibrium results for screening expenditure and ingroup identification for the equilibrium value $S^{*}$ of the extent of using stereotypic perceptions? According to (2) $S^{*}$ equals $R^{S^{*}} /\left(R^{S^{*}}+R^{T^{*}}\right)$. Hence, $S^{*}$ is, via the reliabilities $R^{S^{*}}$ and $R^{T^{*}}$, determined by the simultaneous equilibrium values $I^{*}$ of ingroup identification and $X^{*}$ of screening expenditure. A rise in $X^{*}$ raises the reliability of individual productivity information $R^{T^{*}}$, and hence lowers $S^{*}$, whereas a rise in $I^{*}$ raises the reliability of stereotypic productivity information $R^{S^{*}}$, and hence raises $S^{*}$. This implies

Corollary 2 If absolute risk aversion $\left|U^{\Pi \prime \prime}\left(\hat{\Pi}_{0}^{S}\right)\right|$, and hence self-relevant uncertainty, increases c.p., screening expenditure $X^{*}$ rises (Proposition 1$)$, ingroup identification $I^{*}$ does not change (Corollary $1 \mathrm{~b}$ ), and hence stereotyping $S^{*}$ unambiguously falls.

This result is consistent with the finding of Tiedens and Linton (2001) that stronger uncertainty-related emotions lead to a more thorough look at the individual information at hand and less reliance on stereotypes (see Sect. 1). ${ }^{18}$ We can then easily derive (see Appendix A):

Proposition 3 There is a unique equilibrium level $S^{*}$ of the extent of using stereotypes given by

$$
S^{*}=\beta\left(I_{0}+\frac{\beta m\left|U^{\Pi^{\prime}}\left(\hat{\Pi}_{0}^{S}\right)\right|}{\alpha\left|U^{I \prime \prime}\left(I_{0}\right)\right|}\right) \frac{1}{p} \sqrt{\frac{2 m}{\alpha r\left(\hat{\Pi}_{0}^{S}\right)}},
$$

if the inequality in (8) holds.

Thus, the extent of using stereotypes depends positively on the marginal productivity $\beta$ of ingroup identification in raising the reliability of stereotypic information and the marginal opportunity cost $m U^{\Pi^{\prime}}\left(\hat{\Pi}_{0}^{S}\right)$ of screening expenditure, and negatively on the marginal productivity $\alpha$ of screening expenditure in raising the reliability of stereotypic information, the rate of increase $\left|U^{I \prime \prime}\left(I_{0}\right)\right|$ of the marginal cost of ingroup identification, absolute risk aversion $\left|U^{\Pi \prime \prime}\left(\hat{\Pi}_{0}^{S}\right)\right|$ (or $r\left(\hat{\Pi}_{0}^{S}\right)$ ), and product price $p$. This expression has interesting implications for the effects of competition and other factors on discrimination, which will be examined in the next section. ${ }^{19}$

\footnotetext{
18 It is interesting to compare Corollary 2 with the implication of the theory of tolerance of Corneo and Jeanne (2009) that more uncertainty about occupational outcomes and traits leads to socialization towards more tolerant values as a risk-diversification strategy. In its turn, this will presumably elicit less stereotyping and discrimination. However, in this theory the uncertainty is exogenous unlike the endogenous $U C=\sigma^{2}$ in our model (see Assumption 5 and relation (6)), and the mechanisms are quite different.

19 If the inequality in (8) does not hold, and hence $X^{*}=0, R^{T^{*}}=\alpha X^{*}$ is zero as well. This implies $S^{*}=1$, i.e., estimates of the individual productivities of candidate team members are purely based on stereotypic perceptions (3). Since this case of zero screening expenditure, and hence, e.g., no job interviews, seems rather unrealistic, we will pay little attention to it in the following.
} 


\section{Applications}

\subsection{Effects of competition}

\subsubsection{Effects on identification and screening}

What happens with ingroup identification $I^{*}$ and screening expenditure $X^{*}$ when competition on the supply side of the product market intensifies? Such an increase in competition is conceived as a rise in upward-sloping supply relative to downwardsloping demand in the product market near the equilibrium price $p$. This may be due to either an increase in the number of competing teams or a fall in demand. As a result, $p$, and hence expected profit $\hat{\Pi}_{0}^{S}$, will fall (at given $I$; note that $X=0$ in $\hat{\Pi}_{0}^{S}$ ). This has several effects.

At given variance in profits, the fall in expected profit will raise the risk of negative profits, i.e., of going bankrupt, for the employers. Intuition suggests that this will raise the self-relevant uncertainty of employers. According to our interpretation in Assumption 5 of self-relevant uncertainty $S R U C$ as the ex ante expected utility loss due to the uncertainty $U C=\sigma^{2}$ in the productivity of a new team member, self-relevancy $S R=\frac{1}{2}\left|U^{\Pi \prime \prime}\left(\hat{\Pi}_{0}^{S}\right)\right| p^{2}$ should then increase. For many specifications of utility function $U^{\Pi}(\Pi)$ absolute risk aversion measure $\left|U^{\Pi \prime \prime}\left(\hat{\Pi}_{0}^{S}\right)\right|$ rises when $\hat{\Pi}_{0}^{S}$ falls (but not for all; e.g., for the additive quadratic specification $\left|U^{\Pi \prime \prime}\left(\hat{\Pi}_{0}^{S}\right)\right|$ remains constant). On the other hand, the fall in product price $p$ suppresses $S R$ via the factor $p^{2}$. This effect appears since the fall in $p$ directly lowers the risk $p^{2} \sigma^{2}$ in revenue $p q_{i}$ from a new team member, i.e., less is at stake in absolute money terms. For the intuitively expected net rise in self-relevancy $S R$, and hence in self-relevant uncertainty $S R U C$, to occur, the relative rise in risk aversion $\left|U^{\Pi \prime \prime}\left(\hat{\Pi}_{0}^{S}\right)\right|$ should be greater than the relative fall in $p^{2}$. To see when this may hold, we approximate utility function $U^{\Pi}(\Pi)$ by the common power function

$$
\begin{aligned}
& U^{\Pi}(\Pi)=\frac{\Pi^{\rho}}{\rho}, \quad \rho<1, \quad \rho \neq 0, \\
& U^{\Pi}(\Pi)=\ln \Pi, \quad \rho=0 .
\end{aligned}
$$

This implies $\left|U^{\Pi \prime \prime}\left(\hat{\Pi}_{0}^{S}\right)\right|=(1-\rho) \hat{\Pi}_{0}^{S^{-2+\rho}}$. Empirical evidence is generally consistent with values of $\rho$ in the range of -3 to -1 (Nicholson 1998, p. 226), and since the relative fall in expected profit $\hat{\Pi}_{0}^{S}$ is greater than the relative fall in product price $p$, it easily follows that for $\rho \leq 0$ the relative rise in $\left|U^{\Pi \prime \prime}\left(\hat{\Pi}_{0}^{S}\right)\right|$ is greater than the relative fall in $p^{2}$ (see Appendix B for the derivation). Thus, if employers are not much less risk averse than generally measured, self-relevancy $S R=\frac{1}{2}\left|U^{\Pi \prime \prime}\left(\hat{\Pi}_{0}^{S}\right)\right| p^{2}$, and hence self-relevant uncertainty $S R U C$, rises as competition increases. By the same token, the expected marginal benefits of screening expenditure and ingroup identification in reducing self-relevant uncertainty, as given by the left-hand sides of conditions (7) and (11), will rise as well. This arouses incentives to spend more resources on screening of candidate team members as well as to identify more strongly with the ingroup. 
However, (13) implies that these incentives are not sufficient to lead to a rise in equilibrium identification $I^{*}$, simultaneous with screening $X^{*}$ (see Corollary $1 \mathrm{~b}$ ). For that a change in one of the determinants of identification in (13) is needed. Interestingly, one determinant that does change is the marginal utility of profit $U^{\Pi^{\prime}}\left(\hat{\Pi}_{0}^{S}\right)$. This rises as competition increases, and hence profits drop. Consequently, the expected marginal cost of screening as given by the right-hand side of (7) rises. This means that employers expect a higher opportunity cost of their screening expenditures when their expected profits are lower since the expenditures will then weigh more heavily on their budgets (this implies an income effect of lower profits on screening expenditure). As a result, equilibrium screening $X^{*}$, conditional on identification, will only increase if its marginal benefit rises more than its marginal cost (at the initial $X^{*}$ ). According to (7), this holds if and only if $\left|U^{\Pi \prime \prime}\left(\hat{\Pi}_{0}^{S}\right)\right| p^{2}$ rises relatively more than $U^{\Pi^{\prime}}\left(\hat{\Pi}_{0}^{S}\right)$ as competition increases, and this is equivalent to a rise in Pratt's measure of absolute risk aversion $r\left(\hat{\Pi}_{0}^{S}\right)$ times $p^{2}$ (see (8)). Intuition suggests that this absolute risk aversion measure will rise as profits fall, but again this holds only for certain specifications of utility function $U^{\Pi}(\Pi)$ like power function (15) (Nicholson 1998, pp. 224-225). For this function $r\left(\hat{\Pi}_{0}^{S}\right)=(1-\rho) \hat{\Pi}_{0}^{S^{-1}}$, implying that the relative rise in $r\left(\hat{\Pi}_{0}^{S}\right)$ is even greater than the relative fall in $p$, but not necessarily greater than the relative fall in $p^{2}$. Appendix B shows that for expected profit $\hat{\Pi}_{0}^{S}$ greater than total production costs $C$ the relative rise in $r\left(\hat{\Pi}_{0}^{S}\right)$ is actually smaller than the relative fall in $p^{2}$, whereas for lower $\hat{\Pi}_{0}^{S}$ the reverse holds. Hence, for $\hat{\Pi}_{0}^{S}$ greater than $C$ the marginal cost of screening rises more than its marginal benefit, resulting in falling conditional screening as competition increases. On the other hand, as $\hat{\Pi}_{0}^{S}$ has fallen below $C$, the marginal benefit of screening starts to rise more than its marginal cost, resulting in rising screening as competition increases.

In contrast to the marginal cost of screening, the marginal cost of identification, which is given by the right-hand side of (11), does not change as competition increases since it is non-monetary. This implies that equilibrium identification, conditional on screening, unambiguously rises as competition increases. Moreover, (13) shows that equilibrium identification, simultaneous with screening, unambiguously rises as well. This is due to the rise in marginal screening cost, which leads to substitution of screening by identification in reducing self-relevant uncertainty. This substitution works as follows: the fall or less strong rise in screening due to the rise in its marginal cost lowers the reliability of individual productivity information, which raises productivity risk $\sigma^{2}$ according to (6). This raises the marginal benefit of identification (11), and hence leads to higher identification. In its turn, this raises the reliability of stereotypic productivity information, which lowers risk $\sigma^{2}$, and hence marginal screening benefit, leading to less screening, etc., until screening and identification stabilize on a new simultaneous equilibrium.

For screening, simultaneous with identification, the negative feedback of rising identification on screening adds to the direct negative effect of a higher marginal screening cost, and both effects counteract the positive effect of a higher marginal screening benefit due to the higher risk aversion $\left|U^{\Pi \prime \prime}\left(\hat{\Pi}_{0}^{S}\right)\right|$. Appendix B shows that, in the case of power function (15) with $\rho<\frac{1}{2}$, the negative feedback effect of a higher initial identification dominates for sufficiently low profit $\hat{\Pi}_{0}^{S}$, implying falling 
screening, simultaneous with identification, when competition increases. ${ }^{20}$ For $\hat{\Pi}_{0}^{S}$ higher than production cost $C$ the negative effect of a higher marginal screening cost dominates (see above), and there may be an intermediate range of $\hat{\Pi}_{0}^{S}$ lower than $C$ where the positive effect of a higher marginal screening benefit dominates, implying rising simultaneous screening as competition intensifies. However, the latter effect is not strong enough to prevent identification from rising (in contrast to Corollary $1 \mathrm{~b}$ ).

\subsubsection{Effects on stereotyping}

What are the effects of the changes in identification and screening on the extent of stereotyping $S^{*}=R^{S^{*}} /\left(R^{S^{*}}+R^{T^{*}}\right)$. The rise in simultaneous identification leads to an increase in the perceived reliability of stereotypic information $R^{S^{*}}$, and hence in stereotyping $S^{*}$. This rise in stereotyping is reinforced when simultaneous screening falls, lowering the reliability of individual information $R^{T^{*}}$. On the other hand, when screening rises as competition increases, the direction of change in stereotyping $S^{*}$ is ambiguous. Accordingly, in the case of power function (15) with $\rho<\frac{1}{2}$, there may be an intermediate range of profit $\hat{\Pi}_{0}^{S}$ lower than production cost for which stereotyping falls as competition increases, while for all other levels of $\hat{\Pi}_{0}^{S}$ stereotyping rises (until it reaches value one for very low $\hat{\Pi}_{0}^{S} \leq \tilde{\Pi}_{0}^{S}$; see Appendix B for this and following results).

The effects of competition that have been identified in this section can be summarized as

Proposition 4 When competition on the supply side of the product market increases,

a. for power function (15) with $\rho \leq 0$, self-relevant uncertainty initially rises;

b. ingroup identification $I^{*}$, simultaneous with screening expenditure $X^{*}$, rises;

c. for power function (15) with $\rho<\frac{1}{2}$, screening expenditure $X^{*}$, simultaneous with ingroup identification $I^{*}$, falls except for a possible intermediate range of profit $\hat{\Pi}_{0}^{S}$ lower than production cost $C$, where $X^{*}$ rises, and except for assumedly very small $\hat{\Pi}_{0}^{S} \leq \tilde{\Pi}_{0}^{S}$, where $X^{*}=0$;

d. for power function (15) with $\rho<\frac{1}{2}$, stereotype use $S^{*}$ rises except for a possible intermediate range of $\hat{\Pi}_{0}^{S}$ lower than $C$, where $S^{*}$ falls, and except for very small $\hat{\Pi}_{0}^{S} \leq \tilde{\Pi}_{0}^{S}$, where $S^{*}=1$.

Thus, our psychological model offers arguments why increasing competitive pressure may raise individual statistical discrimination. Competitive pressure may also lead to a rise in group discrimination against the outgroup, but for that to happen some additional conditions need to be fulfilled that will be discussed in Sect. 4.2.

20 At an assumedly very low level $\tilde{\Pi}_{0}^{S}$ of $\hat{\Pi}_{0}^{S}$, screening expenditure becomes zero, and remains zero when $\hat{\Pi}_{0}^{S}$ further falls. This is due to the particular implication of power function (15) that the marginal utility of profit $U^{\Pi^{\prime}} \hat{\Pi}_{0}^{S}$ ) goes to infinity when $\hat{\Pi}_{0}^{S}$ approaches zero. Since this implication seems too extreme, power function (15) may not be a good approximation of $U^{\Pi}\left(\hat{\Pi}_{0}^{S}\right)$ for very low levels of $\hat{\Pi}_{0}^{S}$. 
3.2 Effects of fear of the outgroup, unemployment, and affirmative action

\subsubsection{Fear of the outgroup}

What happens with ingroup identification $I^{*}$, screening expenditure $X^{*}$, and use of stereotypes $S^{*}$ when people, and more in particular employers, start to feel threatened by members of a certain outgroup? For example, the terrorist attacks of 11 September 2001, and later in Madrid and London have raised the fear of Muslim terrorism, and more in general feelings of insecurity vis-à-vis Muslims as a group. This may have raised the benefits of identification with the ingroup of non-Muslims as a psychological defense mechanism against the increased feelings of insecurity. In the context of our model, this is represented by a lower rate of increase $\left|U^{I \prime \prime}\left(I_{0}\right)\right|$ of the marginal cost of ingroup identification. This leads to higher identification with the ingroup (13), thus substituting for lower screening expenditure (8) and inducing higher use of stereotypes (14). Individual statistical discrimination will then rise. This will negatively affect outgroup members with the same productivity $q_{i}$ as ingroup members when the stereotypic perception $\bar{q}^{S O}$ of the average marginal productivity of the outgroup is lower than the perception $\bar{q}^{S I}$ of the average marginal productivity of the ingroup (see Sect. 2.1). If at least one of these stereotypes is incorrect at the expense of the outgroup, the rise in stereotype use leads to an increase in group discrimination against the outgroup as well (see Sect. 4.2).

\subsubsection{Unemployment}

Our model also has implications for a situation in which competition on the supply side of the labour market, and hence unemployment, rises in the ingroup as well as the outgroup. In general, this will raise the number of suitable candidates for a job opening $m$, and hence raise the marginal opportunity cost $m U^{\Pi^{\prime}}\left(\hat{\Pi}_{0}^{S}\right)$ of screening expenditure. This will lower screening expenditure (8), which will be substituted for by a rise in ingroup identification (13), and hence lead to a stronger use of stereotypes (14) (see also Sect. 4.2).

\subsubsection{Affirmative action}

All the resulting increases in discrimination derived so far point to the importance of policy measures like affirmative action to alleviate this problem. Holzer and Neumark (2000) provide evidence for the USA that affirmative action has increased the number of recruitment and screening practices used by employers and has raised employers' willingness to hire stigmatized applicants. In the context of our model, the former increase can be interpreted as a rise in screening expenditure (cf. Altonji and Blank 1999, p. 3190) as a result of an additional marginal benefit of screening. This extra benefit can be subtracted from marginal screening cost, as given by the right-hand side of (7), and so has the effect of making screening less costly relative to ingroup identification. Consequently, screening rises and identification falls, which both lead to a lower use of stereotypes, and hence less individual discrimination. Thus, affirmative 
action not only raises screening, but also enhances the relative cost of identification with the ingroup as a substitute for screening.

\section{Robustness and extensions}

\subsection{Robustness}

A limitation of Proposition 4 in Sect. 3.1 is that only the result under (b) holds for any specification of utility function $U^{\Pi}(\Pi)$ with positive and diminishing marginal utility. To get an impression of the sensitiveness of the results to the specification of $U^{\Pi}(\Pi)$, consider the additive quadratic specification, which has quite different implications from those of the power function. When competition increases, risk aversion measure $\left|U^{\Pi \prime \prime}\left(\hat{\Pi}_{0}^{S}\right)\right|$ then remains constant, and hence, contrary to psychological intuition, self-relevant uncertainty falls due to falling product price. By the same token, the marginal benefits of screening and ingroup identification then fall as well, while the marginal screening cost rises. This implies falling screening and rising identification for all levels of profit $\hat{\Pi}_{0}^{S}$. As a result, stereotype use then rises for all profit levels. Thus, the outcomes are similar to those in the power-function case.

However, the results in Propositions 1-4 and Corollaries 1-2 are somewhat sensitive to relaxing the linear approximations $R^{T}=\alpha X$ and $R^{S}=\beta I$ (Assumptions 4 and 7). Screening expenditure $X^{*}$, conditional on $I$ and simultaneous with $I^{*}$, and ingroup identification $I^{*}$, conditional on $X$, then still depend positively on risk aversion $\left|U^{\Pi \prime \prime}\left(\hat{\Pi}_{0}^{S}\right)\right|$ (or $r\left(\hat{\Pi}_{0}^{S}\right)$ ), but $I^{*}$, simultaneous with $X^{*}$, depends positively on $\left|U^{\Pi \prime \prime}\left(\hat{\Pi}_{0}^{S}\right)\right|$ if $R^{T \prime \prime}\left(X^{*}\right)$ is negative ${ }^{21}$, and negatively on $\left|U^{\Pi \prime \prime}\left(\hat{\Pi}_{0}^{S}\right)\right|$ if $R^{T \prime \prime}\left(X^{*}\right)$ is positive (with analogous dependencies on other exogenous variables; Vendrik and Schwieren 2005). On the one hand, for positive $R^{T \prime \prime}\left(X^{*}\right)$, this implies that when risk aversion rises, the rise in $X^{*}$ and the fall in $I^{*}$ lead to an unambiguous fall in $S^{*}$, as in Corollary 2. On the other hand, when $R^{T \prime \prime}\left(X^{*}\right)$ is negative and risk aversion rises, the resulting rises in $X^{*}$ and $I^{*}$ counteract each other in their effects on $S^{*}$, making the sign of the net effect on $S^{*}$ ambiguous. However, only when $R^{T \prime \prime}\left(X^{*}\right)$ is rather strongly negative, a rise in risk aversion leads to a sufficiently weak increase in $X^{*}$ and a sufficiently strong increase in $I^{*}$ so as to cause a rise in stereotyping $S^{*}$. When increasing competition raises not only risk aversion, but also marginal utility of profit $U^{\Pi^{\prime}}\left(\hat{\Pi}_{0}^{S}\right)$, and hence the marginal opportunity cost of screening, this will only lead to falling identification and rising screening, and hence falling stereotyping, for a sufficiently (but perhaps implausibly) high positive value of $R^{T \prime \prime}\left(X^{*}\right)$. Thus, deviations from the results for stereotyping in Corollary 2 and Proposition $4 \mathrm{~d}$ will only occur for sufficiently strong deviations from linear dependence of the reliability of individual productivity information on screening expenditure.

As mentioned in Sect. 2.1, the model in this paper can also be applied to situations in which there is discrimination in pay besides or instead of hiring. Situation 2 is considered to link our model to Becker's (1957) model of employer discrimination

\footnotetext{
21 This means that the marginal efficiency $R^{T \prime}(X)$ of $X$ in raising reliability $R^{T}(X)$ falls with increasing $X$ at $X^{*}$. See also footnote 13 .
} 
(see the next section). In that situation all firms that compete in the product market have the same two job levels with two different wages, which are given to and identical across the firms. Ingroup members are employed on the higher job level and outgroup members on the lower one. The labour markets for the two job levels are competitive and in market-clearing equilibrium. Employers hire new employees with the highest $p \hat{q}_{i}-w^{g}, g=I, O$, where $w^{g}$ denotes the market wage prevailing for ingroup, respectively outgroup members. In this situation there is discrimination not only in hiring, but also in pay. In Situation 3 new employees are paid according to their estimated marginal productivity $\hat{q}_{i}$, implying discrimination in pay, but not in hiring. For these Situations 2 and 3 the propositions and corollaries can be shown to be identical to those derived above for Situation 1 (see Vendrik and Schwieren 2005), but rising stereotyping now implies increasing discrimination in pay besides or instead of hiring. However, especially in Situation 3 it is odd to assume that the productivities of the incumbent employees are perfectly known (footnote 8) since this should then also hold for the productivity of a new hire some time after her appointment as her productivity has become known. We should then assume risk with respect to the marginal productivities of not only new, but also incumbent employees. In addition, we could allow for risk in other variables like the product price. Assuming independence of variances of productivities and price and making a second-order Taylor expansion of $U^{\Pi}(\Pi)$ around $\hat{\Pi}$ (see Sect. 2.2), additional utility losses due to variances then emerge in (5) and (9). Just like the utility loss due to $\sigma^{2}$, these utility losses may be reduced by the certainty illusion of ingroup identification, implying additional marginal benefits of identification in (11). By raising risk aversion, competitive pressure augments these marginal benefits as well, thus reinforcing the rises in identification, and hence in stereotyping, according to Proposition $4 .^{22}$

Furthermore, although the model is formulated for firms in which hiring and pay decisions are taken by a single residual claimant (the employer), its main implications probably also hold for larger firms in which hiring and pay decisions are taken by recruiting managers. Even if the salaries of these managers do not directly depend on the profit of the firm, contributing to a high profit is important for their reputation in the market of managers. Moreover, they may be committed to the firm and be fired if making wrong hiring decisions. All these factors will make the managers risk averse with respect to risk in productivities of employees (see Sect. 2.2). Still, as recruiting managers may be less committed to the firm than a single employer they may be less risk averse, implying that larger firms may tend to discriminate less. ${ }^{23}$ Another extension of the model is allowing hiring tests to be biased against outgroup members (see Sect. 2.1). This complication can be shown to imply similar effects as

\footnotetext{
22 On the other hand, these additional uncertainties may also lead to search for information to reduce them (like monitoring productivities), which would diminish the reinforcement of the rises in identification and stereotyping. Still, increasing competition will raise the opportunity cost of monitoring expenditures as well, and may hence, by the same mechanisms as in the basic model, lead to more discrimination against the outgroup.

23 An interesting experience in the last (2009) economic crisis in the Netherlands is that large firms are aware of the social norm that the composition of the work force should reflect those of society and the customer population, but that smaller firms are more risk averse. Especially to the latter firms the proverb "unknown, unloved" applies (Vos 2009).
} 
found in the basic model. Our model also allows for the possibility that the outgroup is stereotypically perceived as having a higher, rather than lower, average productivity than the ingroup (see Schwieren et al. 2002). This may, for instance, occur when a group of women perceives a group of men as having a higher average productivity Increasing ingroup identification may, by reinforcing certainty illusions, raise the use of such outgroup-biased stereotypic perceptions as well.

Finally, our model could be extended by allowing for the possibility that the efficiency $\alpha$ of screening expenditure $X$ in raising the reliability of individual productivity information $R^{T}=\alpha X$ is higher for ingroup than for outgroup members due to similar culture, better social networks, etc. This may especially hold for natives versus immigrants. Employers are then found to prefer hiring native workers from local networks to save on recruitment costs and because they feel they are hiring a known quantity (Waldinger and Lichter 2003; McGovern 2007). In such a case the discriminationenhancing mechanism in our model would be reinforced by the mechanism described in footnote 3 .

\subsection{Group discrimination and rationalization of a discriminatory taste}

In Sect. 2.1, Eq. (3) has been shown to imply that a rise in stereotyping $S$ leads to a proportional increase in individual statistical discrimination. In addition, (3) has implications for group discrimination if at least one of the stereotypic perceptions $\bar{q}^{S I}$ and $\bar{q}^{S O}$ of the average marginal productivities in the ingroup and the outgroup is incorrect. Suppose, for instance, that employers have incorrect perceptions of a too low average productivity $\bar{q}^{S O}<\bar{q}^{O}$ of outgroup members, but correct perceptions $\bar{q}^{S I}=\bar{q}^{I}$ of ingroup members. Averaging the individual discrimination measure $S\left(\bar{q}^{S}-q_{i}\right)$ (see Sect. 2.1) over outgroup and ingroup members, respectively, then yields $S\left(\bar{q}^{S O}-\bar{q}^{O}\right)<0$, while $S\left(\bar{q}^{S I}-\bar{q}^{I}\right)=0$. This indicates negative group discrimination against the outgroup. This group discrimination is linearly increasing in stereotyping $S$ as well.

However, in the economic literature on discrimination (see, e.g., Aigner and Cain 1977, p. 177) it has been argued that such incorrect stereotypic perceptions are unlikely to persist in competitive markets since they lead to a competitive disadvantage vis-à-vis competitors with correct or less incorrect perceptions. Hence, either the incorrect perceptions will be corrected by learning about real productivities (cf. Altonji and Pierret 2001) or employers with such perceptions will, in the long run, be competed away. On the other hand, the psychological literature on discrimination shows that even when real differences in average productivity between two groups have disappeared, incorrect stereotypic perceptions of such differences tend to be quite persistent and widespread due to several psychological processes.

First, this stereotypic perception may be deeply ingrained in the mind of employers as a result of socialization and influencing by the media. Relatedly, the stereotypic perception may serve as justification and rationalization of an emotional prejudice and the ensuing discriminatory behaviour against the outgroup (e.g., Snyder and Miene 1994; see also Festinger 1957; Arrow 1973, p. 26). As these processes largely work unconsciously, the resulting emotions and cognitions will not easily change. Quite a 
different kind of reason for the persistence of wrong stereotypic perceptions is implied by the social-psychological BIAS model of Fiedler (1996). This model explains many so-called "biases" in differential perception of in and outgroups from the fact that ingroup samples are usually bigger than outgroup samples. Even when there are no real differences in distribution of individual productivities between the ingroup and the outgroup, the ingroup is then perceived as having a higher average productivity than the outgroup since the pattern of productivity-relevant attributes of the bigger ingroup sample correlates more strongly with the ideal pattern than the pattern of productivity-relevant attributes of the smaller outgroup sample does. ${ }^{24}$ This represents boundedly rational information processing by agents who do not know how to make correct inferences from real-world samples about the underlying populations, and is a persistent phenomenon of human cognition.

Let us therefore consider the above case of incorrect stereotypic perceptions of a too low average productivity $\bar{q}^{S O}<\bar{q}^{O}$ of outgroup members, but correct perceptions $\bar{q}^{S I}=\bar{q}^{I}$ of ingroup members, in more detail. Since in many real-life situations cognitive stereotypes and emotional prejudices go together (Kinder and Sears 1981), we further presume that the incorrect perceptions $\bar{q}^{S O}$ are partially due to rationalization of prejudices and the ensuing discriminatory tastes of the employers against the outgroup. ${ }^{25}$ The incorrect $\bar{q}^{S O}$ lead to stereotypic overestimations $\Delta \bar{q}^{S} \equiv \bar{q}^{S I}-\bar{q}^{S O}$ of the real difference in average productivity $\Delta \bar{q} \equiv \bar{q}^{I}-\bar{q}^{O}$ between the ingroup and the outgroup, and hence to group discrimination against the outgroup in favour of the ingroup. This group discrimination can be measured by discrimination coefficients of the employers, i.e. by the objective expectations of the amounts of money the employers are willing to pay on average for hiring an ingroup instead of an outgroup member in addition to what is implied by the real productivity difference $\Delta \bar{q}$. These discrimination coefficients $D$ are fully based on productivity estimates. Normalizing $D$ by product price $p, D$ is easily derived (Vendrik and Schwieren 2005) to be given by

$$
D=S\left(\Delta \bar{q}^{S}-\Delta \bar{q}\right)
$$

In this expression not only the extent of using stereotypic perceptions $S$, but also the size of the stereotypic overestimation $\Delta \bar{q}^{S}-\Delta \bar{q}$ should be considered as endogenous since social-psychological research (e.g., Lepore and Brown 1999) suggests that not only $S$, but also prejudice, and hence via rationalization $\Delta \bar{q}^{S}-\Delta \bar{q}$, increases with ingroup identification $I$. Vendrik and Schwieren (2005) elaborate this and derive an expression for $\Delta \bar{q}^{S}-\Delta \bar{q}$, which depends positively on $I^{*}$ for $I^{*}$ higher than a certain critical (person-specific) threshold value $I_{c} \geq 0$ and negatively on marginal profit utility $U^{\Pi^{\prime}}\left(\hat{\Pi}_{0}^{S}\right)$. Thus, a higher equilibrium value $I^{*}$ of ingroup identification implies not only a higher use of stereotypes $S^{*}$, but, for $I^{*}>I_{c}$, also a larger stereotypic

\footnotetext{
24 It would lead too far to explain the model in detail here, but see Fiedler (1996); Fiedler (2000). See Fryer and Jackson (2008) for a somewhat related approach in the context of economics.

25 The associated discrimination coefficients $d$ of the employers (Becker 1957) are supposed to be fully rationalized into the (generally heterogeneous) $\bar{q} S O$, leaving no separate contribution of $d$ to the group discrimination in addition to that of $\bar{q} S$.
} 
overestimation $\Delta \bar{q}^{S^{*}}-\Delta \bar{q}$, and hence a higher team discrimination coefficient $D^{*}$ via $\Delta \bar{q}^{S^{*}}-\Delta \bar{q}$ as well as $S^{*}$ by virtue of (16).

However, increasing competition in the product market raises not only identification $I^{*}$, but also marginal profit utility $U^{\Pi^{\prime}}\left(\hat{\Pi}_{0}^{S}\right)$. The latter rise directly lowers stereotypic overestimation $\Delta \bar{q}^{S^{*}}-\Delta \bar{q}$ as the result of an income effect of falling profits (Comanor 1973), according to which falling profits make it relatively more expensive to indulge one's discriminatory taste, and hence suppress the amount of money one is willing to spend on it. As a result, employers will be more cautious in the strength of their stereotypic perceptions. Vendrik and Schwieren 2005 show that, for the linear approximations made, this negative income effect on $\Delta \bar{q}^{S^{*}}-\Delta \bar{q}$ dominates the positive effect of stronger ingroup identification if its critical threshold value $I_{c}$ is lower than its "base level" $I_{0}$ (see Sect. 2.3), but is dominated by it if $I_{c}>I_{0}$. However, in both cases and for power function (15) with $\rho<\frac{1}{2}$, the positive effect on discrimination coefficient $D^{*}$ of a rising stereotype use $S$ as competition increases turns out to dominate for sufficiently low levels of profit $\hat{\Pi}_{0}^{S}$ (see Appendix B).

These results are particularly interesting in relation to the long-run selection mechanism in Becker's theory of employer discrimination. According to this mechanism employers with lower discrimination coefficient $D^{*}$ drive employers with higher $D^{*}$ out of the product market as profits $\hat{\Pi}_{0}^{S}$ approach zero. In particular, if some employers have zero $D^{*}$, these are the only employers to survive in the market, thus eliminating discrimination. However, our psychological model casts doubts on the assumption that some employers have zero $D^{*}$. It is a very general human inclination to identify with one's ingroup, and in many cases stronger identification with one's ingroup will raise the probability of developing a preference for the ingroup or a discriminatory taste against the outgroup. Even employers who initially (say at $I=I_{0}$ ) have a zero discriminatory taste may develop a non-zero one under competitive pressure as this makes them identify more strongly with their ingroup. In our model their identification $I^{*}$ then passes their (person-specific) critical threshold value $I_{c}>I_{0}$. Further, to justify their discriminatory taste, they can rationalize it into a stereotypic overestimation $\Delta \bar{q} S^{*}-\Delta \bar{q}$ of the average-productivity difference between the ingroup and outgroup. The discrimination coefficients $D^{*}$ would then rise above zero and further rise as profits $\hat{\Pi}_{0}^{S}$ fall, by increasing use $S^{*}$ of stereotypic perception $\Delta \bar{q}^{S^{*}}$ as well as rising stereotypic overestimation $\Delta \bar{q}^{S^{*}}-\Delta \bar{q}$ (see above). In the end, even the discrimination coefficient of the surviving employers with the lowest $D^{*}$ in the market would still be substantially positive. ${ }^{26}$

\footnotetext{
26 This argument should be modified when some employers in the market are outgroup members (e.g., women) from the perspective of the ingroup of the majority of other employers (e.g., men). Under competitive pressure these 'outgroup' employers may identify with their own ingroup, and hence not develop a discriminatory taste against their own ingroup. On the other hand, feelings of inferiority or small-sample biases according to the BIAS model of Fiedler (1996) (see above) may still lead to a stereotypic perception of a lower average productivity of their own ingroup as compared to the dominant group. These employers would then develop a rising discrimination coefficient against their own ingroup.
} 


\section{Empirical and experimental evidence}

Evidence that is consistent with the model in Sect. 2 is (of course) given by the socialpsychological findings that we wanted to incorporate in our model (see Sect. 1 and Vendrik and Schwieren 2005 for details). In addition, there are some empirical and experimental studies that provide more indirect evidence for the implications of the model. These studies are reviewed below.

In an extensive empirical study Boone et al. (2004) find that top executive management teams in the newspaper-publisher industry tended to hire more 'similar' team members and fire more 'dissimilar' team members when they had more power vis-à-vis the board of directors and competition from alternative media (particularly television) was strong (interaction effect). Similarity in their study is not related to sex or race, but rather to other demographic characteristics, namely age, career path, industry experience and academic status. A major force underlying this "homosocial reproduction" (Kanter 1977) effect of competition may be identification of the members of a powerful team with their ingroup ("closing ranks" as Boone et al. 2004 call it). This may have led to (more) discrimination against the outgroup, even in the presence of and due to strong competition (see also footnote 23).

Azmat et al. (2006) investigate the possible sources of gender gaps in unemployment in OECD countries. They find a significantly positive interregional correlation of the gender gap with attitudes on whether men are more deserving of work than women. Hence, discrimination against women may explain part of the large gender gap in the Mediterranean countries. Moreover, there turns out to be a weakly significant positive relationship between discriminatory attitude or prejudice and overall unemployment rate across regions within European countries (which they do not describe in their paper). ${ }^{27}$ This suggests that stronger competition on the supply side of the labour market (higher unemployment) may raise prejudice as a result of the higher uncertainty it entails and ensuing identification with the ingroup (cf. Sect. 4.2). In particular, managers who take hiring and pay decisions may be affected by this, inducing them to discriminate (more) against women. ${ }^{28}$

More indirect indications that psychological identification effects of competition on discrimination might be important are given by empirical studies which find no (clear) evidence of a suppressing effect of competition in the product market on employer discrimination (as predicted by Becker 1957, 1971). For example, Shepherd and Levin (1973) and Oster (1975) do not find market power in the product market to influence discrimination, and Baldwin and Johnson (1996) find evidence for discriminatory hiring even if it is obviously inefficient (in the presence of

\footnotetext{
27 For the data of Azmat et al. we linearly regressed prejudice on unemployment rate in 1996 across 143 regions, correcting for country-fixed effects. This yielded a weakly significant positive regression coefficient ( $p$ value 0.07 ). We are indebted to Maia Güell for kindly informing us about the data sources of Azmat et al. and for help with the estimations.

28 Azmat et al. (2003) explain the larger gender gap in unemployment in regions with stronger discriminatory prejudice as the result of a positive interaction effect of this prejudice with overall unemployment. However, we here suggest a different effect which is based on the regression result mentioned in the previous footnote, namely that a higher overall unemployment rate may raise prejudice, and hence lead to more discrimination.
} 
competition in the product market). Szymanski (2000) and Preston and Szymanski (2000) find evidence in the increasingly competitive English soccer league that there was employer discrimination against black players despite of clear performance criteria. More specifically, they show that black players are underpaid in the league, and that this is not due to fan discrimination, but must be employer discrimination. Teams with black players perform even better than other teams, but have lower overall wage bills. Berik et al. (2004) show that increasing competition from international trade between 1980 and 1999 did not reduce the gender wage gap in Korea and Taiwan, but even enhanced it.

Two experimental studies were conducted by us in cooperation with colleagues to test the predictions of the model with respect to competition for the case where there is no individual information on new team members, and hence screening expenditure is zero (Schwieren et al. 2002; Schwieren and Glunk 2008). Equilibrium identification with the ingroup should then rise as competition strengthens (Proposition 2a). The studies provide partially confirming evidence, but further testing is necessary. The experiments of Schwieren et al. (2002) used artificial groups, i.e., "blue" and "red", following the minimal-group paradigm in social psychology (Tajfel et al. 1971), and tried to generate a stereotypic perception $\Delta \bar{q}^{S}$ along the lines of Fiedler's (1996) BIAS model (see Sect. 4.2). The rise in ingroup identification was then supposed to raise the use $S^{*}$ of this stereotype vis-à-vis the use of indications that there was no real difference in average productivity between the ingroup and the outgroup. The experiments found weakly significantly higher discrimination coefficients as competition was stronger, but they tended to be in favour of the outgroup. The latter result is probably related to the artificial nature of the group categories, leading to less ingroup identification than can be expected for real-life categories. Nevertheless, the effect of a rising stereotype use on the discrimination coefficients apparently dominated a possible negative income effect via stereotypic overestimation (see Sect. 4.2).

The study by Schwieren and Glunk (2008) extends the experimental testing to a more complex situation, using a business-simulation game, where categories used are real, namely different nationalities (Dutch and German). In this case the stereotype that German students performed better than Dutch students was realistic, but it was dominated by a strong discriminatory taste of Dutch against German students when competition was perceived to be strong. Moreover, perceived competition correlated significantly positive with ingroup identification. This suggests that ingroup identification can indeed play a major role in raising discrimination when competition increases (see Sect. 4.2).

Finally, there is evidence that general discrimination (in everyday interactions) against Muslims has increased as a result of the terrorist attack of 11 September 2001 (Sheridan and Gillett (2005); Sheridan 2006; see also Bar-Tal and Labin 2001). Sheridan and Gillett (2005), for example, show in a questionnaire study conducted from October to December 2001 in Great Britain that Muslims experienced significant increases in prejudice as measured by being treated rudely, being confronted with negative stereotypes, etc. This is consistent with the prediction from our model that the resulting feelings of insecurity may have led to more identification with the ingroup of non-Muslims, and hence a higher use of stereotypes (and prejudice) 
against Muslims. This implies a rise in individual (and perhaps also group) statistical discrimination of Muslims (see Sect. 3.2.1). According to our model, another cause of this phenomenon may have been the downturn in the business cycle, leading to stronger competition in product as well as labour markets (higher unemployment; see Sect. 3.2.2).

\section{Conclusions}

This paper has developed a model that integrates two opposite responses to increased feelings of uncertainty in hiring and pay decisions which are suggested by socialpsychological research. Employers may raise their screening expenditures on job applicants, but they may also identify more strongly with their ingroup. A simultaneous-equilibrium analysis showed that under certain plausible conditions the former response dominates the latter response, leading to less stereotyping and discrimination. As an application, the effects of increasing competition on the supply side of the product market were analysed. Strengthening competition makes the employers feel more uncertain about their profits, but it also has the effect of raising the opportunity cost of screening expenditures. This elicits substitution of ingroup identification for screening expenditures, and so enhances use of stereotypes, and hence discrimination. Other causes of increasing stereotyping and discrimination are fear of the outgroup (terrorism) and unemployment. On a policy-making level, this calls for affirmative action to motivate employers to invest in screening, and thus to diminish the need for ingroup identification among employers.

The main predictions of the model are reasonably robust to different specifications and extensions. There is empirical and experimental evidence that supports the implications and relevance of the model, but more research is needed to test its predictions. In particular, such research could investigate under which conditions our model performs better than existing models in explaining the effects of competition in the product market on discrimination in the labour market.

The main contribution of this paper is that it integrates an important psychological mechanism into a microeconomic discrimination model and shows how this mechanism can dominate the familiar economic forces. More specifically, social identification and stereotyping are endogenized within a microeconomic model, and this may be of relevance for all domains of economic life where these phenomena play an important role.

Acknowledgments For helpful discussions and comments we want to thank Lex Borghans, Lorne Carmichael, Giacomo Corneo, Frank Cörvers, Peter de Gijsel, Pablo Guillen Alvarez, Rein Haagsma, Georg Kirchsteiger, Doh Shin Jeon, Jörg Oechsler, Gerard Pfann, James Poterba, Erik de Regt, Arno Riedl, Robert Shimer, Jeroen van de Ven, Peter Wakker, Markus Walzl, Geert Woltjer, three anonymous referees, and the participants of the NAKE 2004 Research Day and the EEA 2005 conference in Amsterdam and seminars at Maastricht University and Utrecht University. We are also indebted to Maia Güell for kindly informing us about data sources and help with estimations.

Open Access This article is distributed under the terms of the Creative Commons Attribution Noncommercial License which permits any noncommercial use, distribution, and reproduction in any medium, provided the original author(s) and source are credited. 


\section{Appendix A: Derivations of results in Sect. 2}

The decomposition of $R^{S}$ in footnote 5 corresponds to a decomposition of the prior subjective probability distribution of $q_{i}$ around $\bar{q}^{S}$ into a first-order distribution of $q_{i}$ around the stochastic $\bar{q}$ and a second-order distribution of $\bar{q}$ around $\bar{q}^{S}$ (Camerer and Weber 1992). Assuming that these two distributions are mutually independent, it follows then easily by substitution of $\bar{q}=\bar{q}^{S}+v$ into $q_{i}=\bar{q}+e_{i}$ that the total variance $V(q)$ equals the first-order variance $V(e)$ plus the second-order variance $V(v)$. Variance $V(e)$ can be said to represent first-order risk, while $V(v)$ indicates second-order risk or ambiguity.

Making a second-order Taylor expansion of $U^{\Pi}(\Pi)$ around $\hat{\Pi}$ yields

$$
E^{p}\left[U^{\Pi}(\Pi)\right] \cong U^{\Pi}(\hat{\Pi})+\frac{1}{2} U^{\Pi \prime \prime}(\hat{\Pi}) p^{2} V\left(q \mid q^{T}\right) .
$$

Considering the ante expected value of this expression, we can approximate $E^{a}\left[U^{\Pi}\right.$ $(\hat{\Pi})]$ by $\left.U^{\Pi}\left(\hat{\Pi}^{S}\right)\right]$ and $E^{a}\left[U^{\Pi \prime \prime}(\hat{\Pi})\right]$ by $\left.U^{\Pi \prime \prime}\left(\hat{\Pi}^{S}\right)\right]$, where $\hat{\Pi}^{S} \equiv E^{a}(\hat{\Pi})$. It then follows that

$$
E^{a}\left[E^{p}\left(U^{\Pi}(\Pi)\right)\right] \cong U^{\Pi}\left(\hat{\Pi}^{S}\right)+\frac{1}{2} U^{\Pi \prime \prime}\left(\hat{\Pi}^{S}\right) p^{2} V\left(q \mid q^{T}\right) .
$$

Further, making the plausible assumption that total screening expenditures $m X$ are low relative to $\hat{\Pi}^{S}$, we can approximate $U^{\Pi}\left(\hat{\Pi}^{S}\right)$ by its first-order Taylor expansion with respect to $m X$ around $\hat{\Pi}_{0}^{S} \equiv \hat{\Pi}^{S}$ for $m X=0$, and approximate $U^{\Pi \prime \prime}\left(\hat{\Pi}^{S}\right)$ by $U^{\Pi \prime \prime}\left(\hat{\Pi}_{0}^{S}\right)$, yielding (5).

The posterior conditional variance $\sigma^{2}$ is related to the prior unconditional variance $V(q)$ as $V\left(q \mid q^{T}\right)=S V(q)$ (Aigner and Cain 1977, p. 180). Substituting (2) and $V(q) \equiv 1 / R^{S}$ into this relation, (6) follows.

To derive (12) in Proposition 2, we write $\beta I^{*}+\alpha X$ in (11) as $\beta I_{0}+\alpha X+\beta\left(I^{*}-\right.$ $\left.I_{0}\right) \equiv R_{0}+\beta \Delta I^{*}$, and, for $\beta \Delta I^{*} \ll R_{0}$, approximately solve $I^{*}$, conditional on $X$, from (11). To derive the simultaneous interior $X^{*}$ and $I^{*}$ we should combine (7) and (11). The expressions for the marginal benefits $B_{X}^{*}$ and $B_{I}^{*}$ of $X^{*}$ and $I^{*}$, respectively, on the left-hand sides of (7) and (11) are similar: in fact $B_{X}^{*} / \alpha=B_{I}^{*} / \beta=B_{R}^{*}$, where $B_{R}^{*}$ is the marginal benefit of raising either $R^{T}$ or $R^{S}$ by one unit at $R^{T^{*}}$ and $R^{S^{*}}$. By virtue of (11) and (7) this implies $C_{I}^{*} / \beta=C_{X}^{*} / \alpha$, where $C_{I}^{*}$ and $C_{X}^{*}$ are the marginal costs of $I^{*}$ and $X^{*}$, respectively. Since $C_{X}^{*}$ does not depend on $X^{*},(13)$ easily follows.

To find an expression for $S^{*}$, we first substitute Eq. (8) for $X^{*}$ into $R^{T^{*}}=\alpha X^{*}$, leading to $R^{S^{*}}+R^{T^{*}}=p \sqrt{\alpha r\left(\hat{\Pi}_{0}^{S}\right) / 2 m}$. Substituting (13) into $R^{S^{*}}=\beta I^{*}$, and next substituting the expressions for $R^{S^{*}}$ and $R^{S^{*}}+R^{T^{*}}$ into $S^{*}=R^{S^{*}} /\left(R^{S^{*}}+R^{T^{*}}\right)$, yields an expression for $S^{*}$ as given in Proposition 3 . 


\section{Appendix B: Effects of competition}

For power function (15) with $\rho \leq 0$, a fall in $p$ and the ensuing fall in $\hat{\Pi}_{0}^{S}$ together lead to a net rise in self-relevance $\frac{1}{2} \mid U^{\Pi \prime \prime}\left(\hat{\Pi}_{0}^{S} \mid p^{2}\right.$ of the risk in $q_{i}$. This follows from $\frac{1}{2}\left|U^{\Pi \prime \prime}\left(\hat{\Pi}_{0}^{S}\right)\right| p^{2}=(1-\rho) \hat{\Pi}_{0}^{S^{-2+\rho}} p^{2}=(1-\rho)\left(\hat{\Pi}_{0}^{S} / p\right)^{-2}\left(\hat{\Pi}_{0}^{S}\right)^{\rho}$, which rises when $p$ falls since $\hat{\Pi}_{0}^{S} / p=(p \hat{Q}-C) / p=\hat{Q}-C / p$, where $\hat{Q}$ is expected output quantity and $C$ is production costs, then falls (neglecting minor changes in $\hat{Q}$ due to changes in $\hat{q}_{i}$ ).

For power function $(15) r\left(\hat{\Pi}_{0}^{S}\right)=(1-\rho) \hat{\Pi}_{0}^{S^{-1}}$. Writing $p=\left(C+\hat{\Pi}_{0}^{S}\right) / \hat{Q}$, it then follows that $r\left(\hat{\Pi}_{0}^{S}\right) p^{2}$ is positively proportional to $\hat{\Pi}_{0}^{S^{-1}}\left(C+\hat{\Pi}_{0}^{S}\right)^{2}=C^{2} \hat{\Pi}_{0}^{S^{-1}}+$ $2 C+\hat{\Pi}_{0}^{S}$. This function of $\hat{\Pi}_{0}^{S}$ is easily seen to have a U-shape with minimum point $\hat{\Pi}_{0}^{S}=C$. The effects of competition on $X^{*}$ simultaneous with $I^{*}$ are also determined by the feedback from $I^{*}$ on $X^{*}$ via the term $R^{S} / \alpha$ in (8). Substituting (13) into $R^{S}=\beta I^{*}$ yields an expression for $R^{S} / \alpha$, which, in the case of power function (15), varies as $c_{2} \hat{\Pi}_{0}^{S^{-1+\rho}}$, where $c_{2}=\beta^{2} m /\left(\alpha^{2}\left|U^{I \prime \prime}\left(I_{0}\right)\right|\right)>0$. Combining this with the first term $c_{1}\left(C \hat{\Pi}_{0}^{S^{-1 / 2}}+\hat{\Pi}_{0}^{S^{1 / 2}}\right)$ in (8), where $c_{1}=\sqrt{(1-\rho) /(2 m \alpha)} / \hat{Q}>0$, it is easily derived that $\partial X^{*} / \partial \hat{\Pi}_{0}^{S}$ is positive (negative) if and only if $\hat{\Pi}_{0}^{S}-C$ is greater (smaller) than $-2(1-\rho)\left(c_{2} / c_{1}\right) \hat{\Pi}_{0}^{S^{-1 / 2+\rho}}$. A graph of these functions then shows that for $\rho<\frac{1}{2}$ the "greater-than" inequality, implying falling $X^{*}$ as competition increases, may hold for all values of $\hat{\Pi}_{0}^{S}$, but there may also be an intermediate range of $\hat{\Pi}_{0}^{S}<C$ where the "smaller-than" inequality holds.

Expression (14) for $S^{*}$ implies that, for power function (15), $S^{*}$ varies with competition in proportion to $\left[I_{0}+\left(\alpha c_{2} / \beta\right) \hat{\Pi}_{0}^{S^{-1+\rho}}\right] \hat{\Pi}_{0}^{S^{1 / 2}} /\left(C+\hat{\Pi}_{0}^{S}\right)=\left[I_{0} \hat{\Pi}_{0}^{S^{1 / 2}}+\right.$ $\left.\left(\alpha c_{2} / \beta\right) \hat{\Pi}_{0}^{S^{-1 / 2+\rho}}\right] /\left(C+\hat{\Pi}_{0}^{S}\right)$. Differentiating this expression to $\hat{\Pi}_{0}^{S}$ yields that $\partial S^{*} / \partial \hat{\Pi}_{0}^{S}$ is negative (positive) if and only if $\beta I_{0}\left(\hat{\Pi}_{0}^{S}-C\right)$ is greater (smaller) than $-(1-2 \rho) \alpha c_{2} C \hat{\Pi}_{0}^{S^{-1+\rho}}-(3-2 \rho) \alpha c_{2} \hat{\Pi}_{0}^{S^{\rho}}$. A graph of these functions then shows that, for $\rho<\frac{1}{2}$, the "greater-than" inequality, implying rising $S^{*}$ as competition increases, may hold for all values of $\hat{\Pi}_{0}^{S}$, but there may also be an intermediate range of $\hat{\Pi}_{0}^{S}$ within the interval $\left(\tilde{\Pi}_{0}^{S}, C\right)$ where the "smaller-than" inequality holds.

Vendrik and Schwieren (2005) show that, for employers with $I_{c}<I_{0}$, their stereotypic overestimation $\Delta \bar{q}^{S^{*}}-\Delta \bar{q}$ falls as competition strengthens, for $\hat{\Pi}_{0}^{S}>\tilde{\Pi}_{0}^{S}$ (see footnote 20). This counteracts rises in $S^{*}$ in the discrimination coefficient $D^{*}=$ $S^{*}\left(\Delta \bar{q}^{S^{*}}-\Delta \bar{q}\right)$. However, for the case of power function (15) with $\rho<\frac{1}{2}$, the positive effect on $D^{*}$ of a rising $S^{*}$ can still be shown to dominate the negative effects on $D^{*}$ for sufficiently low $\hat{\Pi}_{0}^{S}$, whereas for sufficiently high $\hat{\Pi}_{0}^{S}$ the negative income effect dominates. Furthermore, there may be an intermediate range of $\hat{\Pi}_{0}^{S}$ (including $\hat{\Pi}_{0}^{S}=C$ ) where $D^{*}$ first rises as competition increases and then falls (due to a rising $\left.X^{*}\right)$. Thus, for $I_{c}<I_{0}, D^{*}$ as a function of $\hat{\Pi}_{0}^{S}$ has, for $\hat{\Pi}_{0}^{S} \geq \tilde{\Pi}_{0}^{S}$, a U-shape with a possible "hump" in the middle part. For employers with $I_{c}>I_{0}$ the rise in $\Delta \bar{q}^{S^{*}}-\Delta \bar{q}$ reinforces the positive effect on $D^{*}$ of a rising $S^{*}$ such that $D^{*}$ rises as well as competition increases with possibly an intermediate range of $\hat{\Pi}_{0}^{S}$ where $D^{*}$ falls, but now with a lower "probability". 


\section{References}

Aigner DJ, Cain GG (1977) Statistical theories of discrimination in labor markets. Ind Labor Relat Rev 30:175-187

Akerlof GA, Kranton RE (2000) Economics and identity. Q J Econ 115(3):715-753

Alchian A, Demsetz H (1972) Production, information costs, and economic organization. Am Econ Rev 62:777-795

Altonji JG, Blank RM (1999) Race and gender in the labor market. In: Ashenfelter O, Card D (eds) Handbook of labor economics, vol 3C. Elsevier, Amsterdam, pp 3143-3259

Altonji JG, Pierret CR (2001) Employer learning and statistical discrimination. Q J Econ 116(1):313-350

Arrow KJ (1973) The theory of discrimination. In: Ashenfelter O, Rees A (eds) Discrimination in labor markets. Princeton University Press, Princeton, pp 91-100

Azmat G, Güell M, Manning A (2006) Gender gaps in unemployment rates in OECD countries. J Labor Econ 24:1-37

Baldwin ML, Johnson WG (1996) The employment effects of wage discrimination against black men. Ind Labor Relat Rev 49:302-316

Bargh JA, Williams EL (2006) The automaticity of social life. Curr Dir Psychol Sci 15:1-4

Bar-Tal D, Labin E (2001) The effect of a major event on stereotyping: terrorist attacks in Israel and Israeli adolescents' perceptions of Palestinians, Jordanians and Arabs. Eur J Soc Psychol 31:265-280

Becker G (1957) The economics of discrimination, 1st edn. The University of Chicago Press, Chicago

Becker G (1971) The economics of discrimination, 2nd edn. The University of Chicago Press, Chicago

Berik GY, van der Meulen R, Zveglich JE (2004) Does trade promote gender wage equity? Evidence from East Asia. Rev Dev Econ 8:237-254

Bodenhauser GV (1993) Emotions, arousal and stereotypic judgements: a heuristic model of affect and stereotyping. In: Macke DM, Hamilton DL (eds) Affect, cognition and stereotyping. Academic Press, San Diego, pp 13-37

Boone C, van Olffen W, van Witteloostuijn A, de Brabander B (2004) The genesis of top management team diversity: selective turnover among top management teams in Dutch newspaper publishing, 1970-94. Acad Manage J 47(5):633-656

Brewer MB (1991) The social self: on being the same and different at the same time. Pers Soc Psychol Bull 17:475-482

Camerer C, Weber M (1992) Recent developments in modeling preferences: uncertainty and ambiguity. J Risk Uncertain 5:325-370

Coate S, Loury G (1993) Will affirmative action policies eliminate negative stereotypes? Am Econ Rev $83: 1220-1242$

Comanor WS (1973) Racial discrimination in American industry. Economica 40:363-378

Cornell B, Welch I (1996) Culture, information, and screening discrimination. J Polit Econ 104(3):542-571

Corneo G, Jeanne O (2009) A theory of tolerance. J Public Econ 93(5-6):691-702

De Cremer D (2001) Perceptions of group homogeneity as a function of social comparison: the mediating role of group identity. Curr Psychol Dev Learn Pers Soc 20:138-146

Festinger L (1957) A theory of cognitive dissonance, Row Peterson, Oxford

Fiedler K (1996) Explaining and simulating judgment biases as an aggregation phenomenon in probabilistic, multiple-cue environments. Psychol Rev 103:193-214

Fiedler K (2000) Beware of samples! A cognitive-ecological sampling approach to judgment biases. Psychol Rev 107(4):659-676

Fiske ST (1998) Stereotyping, prejudice, and discrimination. In: Gilbert DT, Fiske ST, Lindzey G (eds) The handbook of social psychology, 4th ed. McGraw Hill, New York, pp 357-414

Fryer RG, Jackson MO (2008) A categorical model of cognition and biased decision making, J Theor Econ Contrib Theor Econ 8(1), article 6

Haagsma R (1993) Is statistical discrimination socially efficient? Inf Econ Policy 5:31-50

Hendricks W, DeBrock L, Koenker R (2003) Uncertainty, hiring and subsequent performance: the NFL draft. J Labor Econ 21(4):857-886

Hewstone M, Rubin M, Willis H (2002) Intergroup bias. Annu Rev Psychol 53:575-604

Holzer H, Neumark D (2000) What does affirmative action do? Ind Labor Relat Rev 53:240-271

Hunt S (1997) Women's vital voices. Foreign Aff 76(4):2-7

Kanter R (1977) Men and women of the corporation. Basic Books, New York 
Kinder DR, Sears DO (1981) Prejudice and politics: symbolic racism versus racial threats to the good life. J Pers Soc Psychol 40:414-431

Lepore L, Brown R (1999) Exploring automatic stereotype activation: a challenge to the inevitability of prejudice. In: Abrams D, Hogg MA (eds) Social identity and social cognition. Blackwell, Malden, pp 141-163

McGovern P (2007) Immigration, labour markets and employment relations: problems and prospects. Br J Ind Rel 45(2):217-235

Mullin BA, Hogg M (1998) Dimensions of subjective uncertainty in social identification and minimal intergroup discrimination. Br J Soc Psychol 37:345-365

Nicholson W (1998) Microeconomic theory; basic principles and extensions. The Dryden Press, London

Oster ShM (1975) Industry differences in the level of discrimination against women. Q J Econ 89:215-229

Phelps ES (1972) The statistical theory of racism and sexism. Am Econ Rev 62:659-661

Preston I, Szymanski S (2000) Racial discrimination in english football. Scott J Polit Econ 47:342-363

Rosen A (2003) Search, bargaining, and employer discrimination. J Labor Econ 21:807-829

Schwieren C, Vendrik MC, de Gijsel P (2002) The power of competition: reducing or reinforcing discrimination? In: Stability and dynamics of power, conference proceedings of IAREP/SABE, pp 346-354

Schwieren C, Glunk U (2008) Mechanisms underlying nationality-based discrimination: a quasi-experiment testing predictions from social psychology and microeconomics. Small Group Res 39:643-672

Shepherd WG, Levin ShG (1973) Managerial discrimination in large firms. Rev Econ Stat 55:412-422

Sheridan LP (2006) Islamophobia pre- and post-September 11th, 2001. J Interpers Violence 21(3):317-336

Sheridan LP, Gillett R (2005) Major world events and discrimination. Asian J Soc Psychol 8:191-197

Shleifer A (2004) Does competition destroy ethical behavior? Am Econ Rev 94(2):414-418

Snyder M, Miene P (1994) On the functions of stereotypes and prejudice. In: Zanna MP, Olson JM (eds) The psychology of prejudice: the Ontario symposium. Erlbaum, Hillsdale, pp 55-89

Szymanski S (2000) A market test for discrimination in the English professional soccer leagues. J Polit Econ 108:590-603

Tajfel H, Flament C, Billig MG, Bundy RP (1971) Social categorization and intergroup behaviour. Eur J Soc Psychol 1:149-178

Tiedens LZ, Linton S (2001) Judgment under emotional certainty and uncertainty: the effects of specific emotions on information processing. J Pers Soc Psychol 81:973-988

Turner JC (1984) Social identification and psychological group formation. In: Tajfel H (ed) The social dimension: European development in social psychology, vol 2. Cambridge University Press, Cambridge, pp 518-538

Vendrik MC, Schwieren C (2005) Identification, screening and stereotyping in labor market discrimination, METEOR Research Memorandum RM/05/014, Faculty of Economics and Business Administration, Universiteit Maastricht, Maastricht

Vos C (2009) Diversiteitsbeleid verslapt door crisis. In: VK banen, Actueel. http://www.vkbanen.nl/ actueel/750152/Diversiteitsbeleid-verslapt-door-crisis.html?utm_source=redactionelenieuwsbrief\& utm_medium=nieuwsbrief\&utm_campaign=20090910. Accessed 10 Sept 2009

Waldinger M, Lichter MI (2003) How the other half works: immigration and the social organization of labor. University of California Press, Berkeley

Weichselbaumer D, Winter-Ebmer R (2007) The effects of competition and equal treatment laws on gender wage differentials. Econ Policy, pp 235-287

Zanna MP, Olson JM (eds) (2004) The psychology of prejudice: the Ontario Symposium, vol 7. Erlbaum Publishers, Hillsdale, NJ 